\title{
ORDENAMIENTO DEL TERRITORIO E INTELIGENCIA TERRITORIAL. UN ENFOQUE APLICADO A CASOS EN LA PLATA (ARGENTINA) Y MINAS (URUGUAY)
}

\author{
Horacio BOZZANO \\ (UNLP-CONICET Argentina)
}

Recibido: 02/05/2014

Aceptado: 30/09/2014

RESUMEN: Un Ordenamiento del Territorio en ciernes y algunas perspectivas de la Geografía en América latina han conocido significativos desarrollos en las tres últimas décadas, produciendo aportes teórico-metodológicos de utilidad: en este diálogo, la Inteligencia Territorial - muy reciente en Latinoamérica- está produciendo notables contribuciones. El trabajo se organiza en dos partes. En la primera, "Teorías y conceptos", se entablan algunos diálogos teóricos entre el Ordenamiento Territorial, la Geografía, la Inteligencia Territorial y una triangulación teórica, procurando rescatar articulaciones, aportes, problemas y aprendizajes emergentes de dichas relaciones. En la segunda parte -"Iniciativas y Métodos"- se exponen aportes que, desde los Métodos Territorii y Stlocus se hicieran al proceso de ordenamiento territorial en el Municipio de La Plata entre 1995 y 2000, así como los aportes que desde Stlocus se hicieran al proceso semejante en la Ciudad de Minas, Lavalleja, Uruguay en 2013 y 2014, ambos en el marco de procesos institucionalizados, en la Municipalidad de La Plata y la Provincia de Buenos Aires, y en la Intendencia de Lavalleja y la Dirección Nacional de Ordenamiento Territorial del Uruguay, respectivamente. Territorii y Stlocus son dos métodos científicos de origen geográfico, con más de una década de puesta a prueba en Procesos de Intervención y Transformación con Inteligencia Territorial. El trabajo cierra con reflexiones, problemas y aprendizajes para futuras investigaciones en materia de Ordenamiento Territorial en Procesos de Intervención y Transformación con Inteligencia Territorial en Latinoamérica.

PALABRAS CLAVE: Ordenamiento del Territorio, Inteligencia Terrritorial, Geografía, Métodos, Transformación

REGIONAL PLANNING AND TERRITORIAL INTELLIGENCE. APPROACH APPLIED TO CASES IN LA PLATA (ARGENTINA) AND MINAS (URUGUAY)

ABSTRACT: An incipient Territory Arrangement and some perspectives of Geography in Latin America have experimented important developments in the last three decades, producing theoretical and methodological contributions of use: in that dialogue, Territorial Intelligence - very recent in Latin America - is producing important contributions. This paper is organized in two parts. In the first part, "Theories and concepts", there are some theoretical dialogues between Territorial Arrangement, Geography, Territorial Intelligence and a theoretical triangulation, seeking for articulations, contributions, problems and learning emerging from said relations. In the second part - "Initiatives and methods"- there are contributions made from Territorii and Stlocus methods to 
the process of territorial arrangement of the Town Hall of the City of La Plata between 1995 and 2000, and also the contributions made by Stlocus to a similar process in the city of Minas, Lavalleja, Uruguay between 2013 and 2014, both in the framework of institutionalized processes, in the Town Hall of the city of La Plata and in Buenos Aires Province, and in the Intendant's office of Lavalleja and the National Direction of Territorial Arrangement of Uruguay, respectively. Territorii and Stlocus are two scientific methods of geographic origin, with more than a decade of trial in Intervention and Transformation Processes with Territorial Intelligence. The paper concludes with considerations, problems and learning for future investigations in Territorial Arrangement in Intervention and Transformation Processes with Territorial Intelligence in Latin America.

KEY WORDS: Territorial Arrangement - Territorial Intelligence - Geography - Methods - Transformation

\section{INTRODUCCION}

Mientras buena parte de las perspectivas en Ordenamiento Territorial (OT) continúan más próximas a visiones tecnocráticas, discursivas y alejadas de la gente que vive en cada territorio, varios abordajes de la Geografía, coherentes con su historia, continúan navegando en la construcción de su epistemología sin alejarse de visiones descriptivas y explicativas, situación presente tanto en tradiciones neoclásicas, como críticas. No se trata de caer en extremos; la convivencia entre los denominados desde 1987 por Boaventura de Sousa Santos (2009) paradigmas cientificos dominantes y emergentes perdurará durante varias generaciones. El caso de la Inteligencia Territorial -en adelante IT- con tres décadas en Europa y de reciente introducción en Latinoamérica, es muy diferente: institucionalizado desde 2011 está produciendo notables aportes en un conjunto de más de 70 colectivos de investigación en cuatro continentes que participan de la INTI International Network of Territorial Intelligence, con sede mundial en Besançon (la MSHE, en la Université de Franche-Comté y el CNRS) y con sede latinoamericana en La Plata (Equipo de Investigación TAG, en el Instituto IdIHCS en la Universidad Nacional de La Plata y el CONICET). Hoy participan 39 Universidades de América Latina de la Red Científica latinoamericana TAG Territorios Posibles -integrante de INTI- cada una con un fecundo quehacer en Procesos de Intervención y Transformación con IT: una de sus once líneas de investigaciónacción es precisamente el OT con IT, objeto del presente trabajo. ${ }^{1}$

${ }^{1}$ En las conclusiones se hace referencia a sus once líneas de investigación-acción. La INTI Network es promovida por el CNRS Centre National de la Recherche Scientiphique de Francia y animada en el período 2011-2014 por siete Universidades de cinco países -Francia, España, Argentina, Bélgica e Italia- y por organismos científicos nacionales de Francia, Argentina y Bélgica, integrantes del GDRI Groupe de Recherche International de la INTI. Participan unos 70 grupos de investigación-acción de cuatro continentes, así como instituciones públicas y organizaciones intermedias. La INTI www.territorial-intelligence.eu funciona con cuatro ejes 
Los objetivos que organizan el trabajo son: 1) ofrecer aportes teóricos a la co-construcción de un Ordenamiento del Territorio con Inteligencia Territorial en el marco de un paradigma científico emergente produciendo la articulación compleja y gradual de Teorías Sociales, Territoriales y de la Transformación; 2) presentar un apretado resumen de los métodos Stlocus y Territorii en clave de Inteligencia Territorial con el fin de ofrecer medios para entender, explicar, proyectar y ejecutar proyectos de Ordenamiento del Territorio de la manera más integral y participativa posible; y 3) exponer dos iniciativas concretas -en La Plata, Argentina y Minas, Uruguay- instrumentadas en el marco de procesos de Ordenamiento del Territorio desde las instituciones que regulan estos temas y con participación de un buen número de actores. El trabajo cierra con reflexiones, problemas y aprendizajes para futuras investigaciones en materia de Ordenamiento del Territorio en Procesos de Intervención y Transformación con Inteligencia Territorial en Latinoamérica.

\section{TEORIAS Y CONCEPTOS}

\section{II.1 Ordenamiento del Territorio: política, ciencia, técnica y compromiso}

Normalmente cada uno de nosotros ingresa al OT desde nuestro lugar: el gobierno, una determinada ciencia, un quehacer técnico o administrativo específico, las comunidades, frecuentemente poco consideradas, los actores económicos con sus intereses, los medios de comunicación y otros actores; y finalmente ocurre que no terminamos de renunciar de manera suficiente a incorporar una teoría y una práctica del OT más integral y eficiente que de sustento científico y utilidad a la gente y sus territorios. Como veremos más adelante, el OT con IT incorpora desde el primer minuto los tres pilares de la regulación en Max Weber -no sólo al Estado, sino a las comunidades y al mundo económico- junto a la "cuarta pata de una mesa": el conocimiento científico y técnico aplicado, en este caso al OT, necesariamente desde una perspectiva integral. En este marco, entendemos al OT como la dificilísima empresa de vincular una política, una actividad científica, una actividad técnica, un compromiso con la gente y un compromiso

(Territorio, Inteligencia, Gobernanza y Observación) y dos temas transversales (Vulnerabilidad y Género), y se prevé su renovación para el período 2015-2020. En el caso de América Latina, TAG Territorios Posibles con sede en el Instituto de Investigación IdIHCS UNLP-CONICET en La Plata, Argentina, es la Red Científica Latinoamericana en Inteligencia Territorial integrante de la INTI. http://territoriosposibles.fahce.unlp.edu.ar TAG es Territorio Actores Gobernanza para la Transformación 
con el territorio, todo ello en un mismo territorio. Este alcance tan complejo hace del OT, en la mayoría de los casos, algo imposible de ejecutar al pie de la letra.

MASSIRIS (2002:12-31) al referirse a políticas y/o actuaciones de ordenación del territorio de quince países latinoamericanos examina seis rasgos que caracterizan dichas políticas: 1) origen y naturaleza diversa, 2) desarrollo incipiente e intención de globalidad; 3) intención de articulación entre actuaciones sectoriales y territoriales en las normas; 4) desarticulación y descoordinación institucional en la práctica; 5) débil visión prospectiva, y 6) escasa participación social. En buena medida coincidimos con los resultados de su análisis. "En general, es notable en los países latinoamericanos, la ausencia de una cultura de la planificación participante y el escaso dominio de metodologías de consensos y de resolución de conflictos en los procesos de concertación, que permitan, por ejemplo, evitar que los actores poderosos impongan sus intereses individuales por encima del interés colectivo" (Massiris, 2002: 4,10, 31) Hoy, doce años después, puede afirmarse que estamos mejor en América Latina en esta materia, aunque por cierto queda mucho por hacer.

Al referirse a América Latina, Montes Lira “....destaca un creciente proceso de aprobación de Planes de Ordenamiento Territorial en diversas ciudades de la región (como) importantes procesos de adecuación normativa, especialmente a través de la elaboración de Leyes Marco de Ordenamiento Territorial... En definitiva, se trata de poner en práctica el dicho de que el mejor plan es el plan que realmente se puede ejecutar". (MonTES LiRA, 2001:16-17) Agregamos a esta frase la siguiente: el mejor plan es el plan hecho con las cuatro "patas de la mesa" de la IT -políticos, comunidades, científicos, empresarios- y que realmente se puede ejecutar.

Con Sergio Resa nos referimos a una definición más abarcativa que el OT propiamente dicho: "La Planificación, Ordenamiento y Gestión Territorial (POGesT) es el proceso reflexivo orientado a producir transformaciones en conciencias, en objetos y en acciones a los efectos de promover un desarrollo deseable del territorio y de sus lugares, mediante la aplicación de un objeto de estudio y de un objeto de intervención determinado. Este proceso supone su inclusión en una POGesT más amplia y la derivación del mismo en intervenciones de POGesT más particularizados. El proceso reflexivo supone incorporar lo real, lo pensado, el pasado en el presente, la anticipabilidad -como condición de anticipación- y lo posible" (Bozzano, 2009:98) En esta definición, política, ciencia, técnica, escalas de trabajo y compromiso deben estar presentes. 


\section{II.2 Ordenamiento del Territorio, diálogos entre tres tipos de Teorías}

Un OT con IT parte de un mejoramiento en el diálogo entre Teorías Territoriales, Sociales y de la Transformación; dicho en otras palabras: qué territorio, qué sociedad y qué transformación estamos en condiciones de contribuir a promover y poner en hechos desde el ordenamiento territorial? Si coincidimos que la teoría y la práctica del OT debe contribuir en los hechos, más que en nuestras oficinas públicas, universidades y laboratorios científicos, a producir círculos virtuosos de transformación en territorios, ambientes y sociedades más multiculturales, biodiversos, sobrios (o austeros) y con personas más felices, entonces no podemos desde la ciencia argumentar que sólo con Teorías del Territorio o de su Ordenamiento vayamos a resolver estas complejas cuestiones.

Al referirnos a la naciente Inteligencia Territorial latinoamericana (BozZANO, 2012:93-107) propusimos cinco triangulaciones entre la ciencia y la gente para comunicar el estado de este nuevo campo científico multidisciplinario en América Latina. ${ }^{2}$ De ellas, nos interesa aquí la segunda triangulación preferentemente teórica, bien compleja, que refiere a la sinuosa articulación de Teorías Territoriales, Sociales y de la Transformación; como veremos a continuación es muy difícil escindir lo que en la realidad -entre estas tres teorías- está unido, no sólo como planteo conceptual, sino práctico. Luego de haber teorizado y aplicado, en particular con Sergio Resa, en un buen número de municipios, se entiende que el OT está en condiciones de respetar las normas vigentes de cada gobierno y articular en los hechos -en complejas empresas- Teorías Territoriales, Sociales y de la Transformación. Sin duda que se tratará de un trabajo más arduo que el realizado en una oficina o laboratorio alejado de la gente, pero también será más útil y virtuoso. La evocación de un caso puede ser elocuente: en una investigación sobre Industria y Territorio en la Región Metropolitana de Buenos Aires (BozzANo, 1999:276-283) se verificó que 85\% de las industrias de uno de sus Municipios más industriales -Avellaneda- estaban fuera de las zonas industriales del Código vigente de Ordenamiento Territorial. Cuántos Planes de OT en América latina se han hecho sin conocer lo suficiente los procesos sociales, económicos, políticos y territoriales, así como los rasgos de transformación más virtuosa que se pretendían lograr para hacer unos lugares mejores? En el caso de América Latina buena parte de lo regulado no es respetado y el OT termina desvirtuándose y desva-

${ }^{2}$ En apretado resumen la primera triangulación es paradigmática, en base a B. de Sousa Santos, la segunda es teórica como aquí intentamos aplicar, mientras que las tres restantes refieren al proceso (fases concretas del proyecto u objeto): estudio (o diagnóstico), intervención (topdown y bottom-up simultáneos) y transformación (qué soy, qué necesito y qué quiero: identidades, necesidades y sueños) 
lorizándose; la circunsatncia que las excepciones a las normas terminen siendo moneda corriente no son sino un indicador de estas insuficiencias.

\section{II.2-a. Teorías Territoriales}

En materia de Teorías Territoriales, la Geografía en América Latina en las tres últimas décadas goza de buena salud. Brasil está presente en nuestros EGAL Encuentros de Geógrafos de América Latina de manera mayoritaria; su producción científica tiene notable incidencia en toda nuestra Geografía. Habiendo muchas perspectivas geográficas, rescatamos “....una Geografía, que no sólo es geo-grafein, sino geo-explanans y geo-transformare, una geografía de la descripción, la explicación y la transformación." (Bozzano, 2013a:10-16). Coincidimos con Saquet: "Estudando várias obras centradas no conceito de território de distintos autores considerados fundamentais na renovação da geografia e de outras ciências, percebemos que todos trabalham, embora com concepções diferentes, com a ideia da construção social do território: Jean Gottmann, Giuseppe Dematteis, Francesco Indovina, Donatella Calabi, Massimo Quaini, Alberto Magnaghi, Claude Raffestin, Robert Sack, Edward Soja, Milton Santos, Bertha Becker, Manuel Correia de Andrade, Arnaldo Bagnasco, Gilles Deleuze, Félix Guattari, entre outros e outras." (SAQUET, 2013b:49)

En nuestro caso retrabajamos teórica y prácticamente los conceptos de territorio y lugar presentes en la Teoría Social Crítica del Espacio o Territorio Usado de Milton Santos, principalmente en su obra "La naturaleza del espacio. Técnica y tiempo. Razón y emoción" (1996). De las numerosas reinterpretaciones de su Teoría, rescatamos cuatro de sus conceptos categoriales más importantes de su desarrollo teórico: los sistemas de objetos y sistemas de acciones, como fijos y flujos, trabajo muerto y trabajo vivo, ocupación y apropiación dialécticamente unidos (1); la técnica, como principal forma de hibridación entre hombre y medio, más que como una escisión de nuestras mentes (2); los acontecimientos en tiempo-espacio representativos de procesos (3), y el poder, en sus relaciones local-meso-globales (4). ${ }^{3}$ En la práctica, y traducción (DE SousA, 2009:143) mediante, esta Teoría se trabaja con los actores: cosas y relaciones juntas, tiempo, técnicas y poder, respectivamente. La articulación se entabla haciendo dialogar interfaces de conocimiento y perspectivas sociales de base construccionista en Long (2007), con estos ejes de análisis del territorio y un buen número de conceptos operacionales derivados y/o relacionados con ellos: lugar, ocupación

3 Sin ser excluyentes, hay aspectos valiosos de estos conceptos categoriales en la obra (Santos, 1996): los sistemas de objetos y sistemas de acciones preferentemente en capítulos 2 y 3 , la técnica en capítulos 1, 7 y 10, los acontecimientos en el capítulo 6, el poder en capítulos 5, 11 y 12, mientras que una brillante síntesis en los últimos dos capítulos del libro: 14 y 15 
territorial, apropiación territorial, territorialidades, espacialidades absolutas, relativas y relacionales, pacto fundacional, huella, impronta, aconteceres homólogos, jerárquicos y complementarios, estilos top-down y bottom-up, etc. ${ }^{4} \mathrm{La}$ triangulación mencionada comienza a tener lugar en la medida que, aplicados a cada objeto o proyecto, se van reconociendo articulaciones entre conceptos territoriales y conceptos sociales o de la transformación.

El territorio es, en primera instancia, una construcción social-natural cooperativa y conflictiva; y en segunda instancia: "Es un lugar de variada escala -micro, meso, macro- donde actores -públicos, privados, ciudadanos, otros- ponen en marcha procesos complejos de interacción -complementaria, contradictoria, conflictiva, cooperativa- entre sistemas de acciones y sistemas de objetos, constituidos éstos por un sinnúmero de técnicas -híbridos naturales y artificiales- e identificables según instancias de un proceso de organización territorial en particulares acontecimientos -en tiempo-espacio- y con diversos grados de inserción en la relación local-meso-global. El territorio se redefine siempre." (Bozzano, 2009:94). El lugar forma parte de un territorio: "Es un patrón de ocupación y apropiación territorial en la micro y/o meso escala que se explica a partir de la puesta en marcha continua, conflictiva y solidaria de aconteceres jerárquicos, homólogos y complementarios, por parte de actores que resignifican conciencias, acciones y objetos de manera perpetua en instancias de un proceso de organización territorial; el lugar se redefine siempre. El lugar es explicado a partir del reconocimiento de territorialidades, vocaciones, racionalidades, procesos, tendencias, actores y espacialidades específicos en cada caso.” (BozzANo, 2009:95)

Articulando en buena medida estos tres tipos de teorías Saquet plantea: "La Geografía que producimos necesita, cada día más, estar enlazada a los procesos de desarrollo, caracterizándose como una Geografía que busca la cooperación para el desarrollo.. Para ello, es fundamental, nuestro compromiso, no sólo como investigadores y formadores en distintos niveles académicos, sino en proyectos, programas y planes de desarrollo, produciendo conocimiento que pueda ser utilizado efectiva y participativamente por los sujetos estudiados en cada territorio urbano y rural.. ... Las actuales relaciones de poder, en el modo capitalista de producción, necesitan ser absorbidas y reordenadas; las identidades culturales, valorizadas y preservadas; las redes necesitan ser adecuadas para facilitar la cooperación y la solidaridad.... Ir contra la clase dominante es muy difícil, y se trata de realizar una serie de consideraciones en favor de una praxis de transformación social y territorial" (SAQUET: 2013a:115-121); en la misma línea del autor,

${ }^{4}$ Pueden consultarse en Bozzano, H (2009, $2^{\circ}$ ed 2012), los capítulos 4, 5 y 6 (pp.101-197) donde se exponen 37 conceptos operacionales de base miltoniana. 
planteamos que se trata de una praxis de transformación individual (en cuerpo y alma), social (o comunitaria), territorial (o ambiental) y decisional.

\section{II.2.b Teorías Sociales}

En las últimas décadas, desde la Sociología y otras Ciencias Sociales, se argumentaba acerca de insuficiencias y debilidades de Teorías Geográficas y Territoriales; si bien aún los diálogos no son armonía pura, hoy el status científico de la Geografía es más sólido, y atravesamos nuevos aires. Para pensar y ejecutar un OT con IT, habiendo muchísimos aportes en materia de Teorías Sociales -no sólo Sociológicas- rescatamos aquí tres perspectivas. En primer lugar, nuestro intento por superar la tensión presente en la Sociología entre la acción, la agencia en M.Weber y el sistema, la estructura en E.Durkheim, presente en E.de ÍPolA (2004), incorpora una tercera arista: los lugares, en una Tríada de Procesos, Lugares y Actores, en H.BozzANo (2009); en segundo lugar haremos referencia a las interfaces de conocimiento en N.LoNg (2007), mientras que en tercer lugar aludiremos a la investigación-acción participativa en O.FALs BORDA $(1986,2009)$ y M.MonTERo $(1984,2004)$

Incorporamos sendos"...puntos de vista del sistema o la estructura en E. Durkheim y de la acción o la agencia en Weber" (DE IPOLA, 2004:14-15), ya no desde perspectivas sociológicas, sino en campos que alcanzan a todas las ciencias sociales: Sociología, Ciencia Política, Antropología, Geografía, Historia, Economía, Psicología, Comunicación, Trabajo Social, etc.; vale decir que se trabaja articulando visiones de macro procesos o macro-estructuras o macro-sistemas -sociales, ambientales, políticos, económicos, culturales, etc.- presentes en cada micro, meso o macro-proyecto concreto, con visiones de saberes de actores o sujetos partícipes de cada proyecto: un ciudadano, un productor, un político, un técnico, un financiador, etc. Esta tensión entre la acción y el sistema, propia de los orígenes de la teoría sociológica, se ha ido profundizando en mayor medida con otra tensión, cuando desde algunas ciencias sociales -Geografía, Urbanismo, Ordenamiento Territorial, Desarrollo Endógeno, Antropología, Economía Espacial y otras- se intenta incorporar al territorio y sus lugares. (Figura 1) La hipótesis es la siguiente: "Habida cuenta del carácter complejo de la realidad social -cualquiera sea- no podemos pensar que el punto de vista del sistema excluya a los puntos de vista del territorio y de la acción; ni tampoco que el punto de vista del territorio excluya los del sistema y de la acción; ni que el punto de vista de la acción excluya a los puntos de vista del sistema y del territorio." (Bozzano, 2009:242) 
Figura 1. Tríada social de procesos, lugares y actores

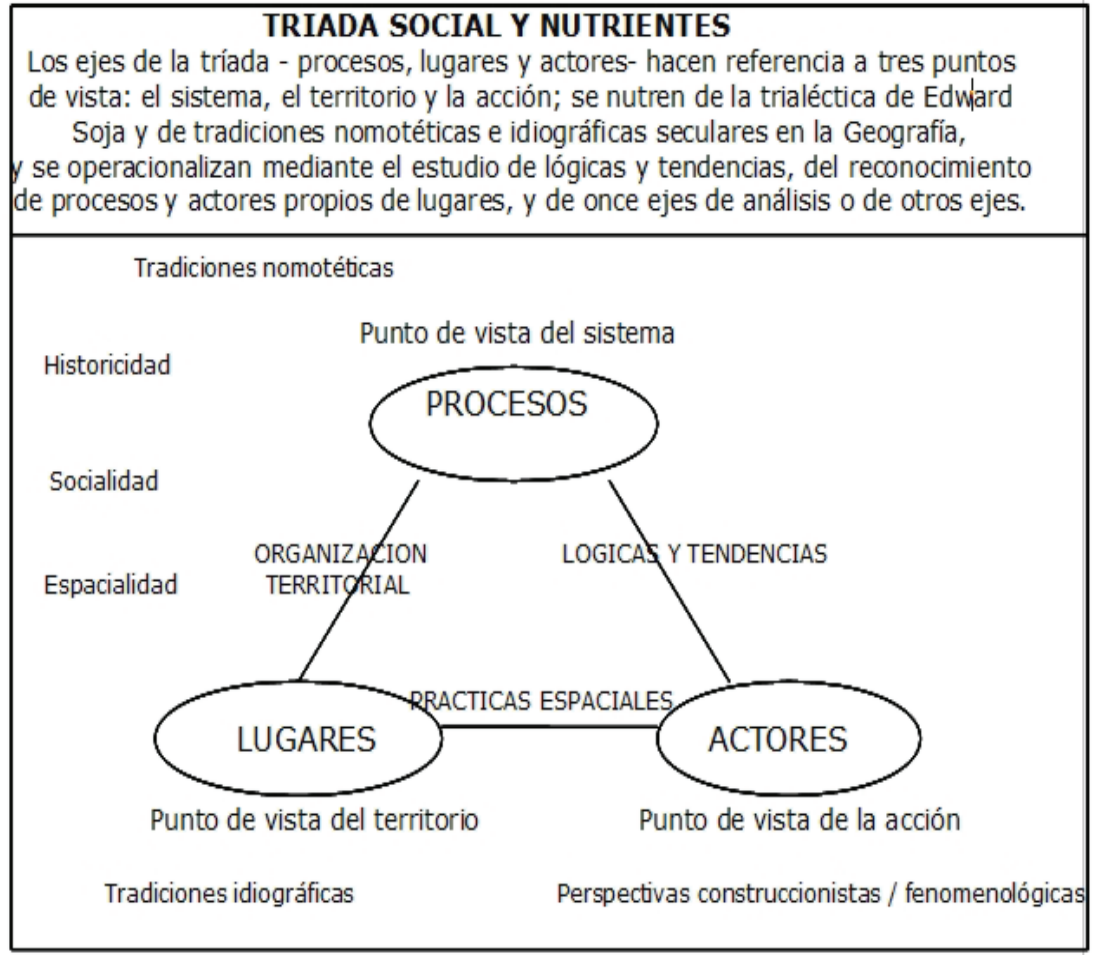

FUENTE: Bozzano, 2009, 249

Una de las maneras en que las perspectivas de la acción y el sistema se procuran aplicar a la naciente IT latinoamericana es con los aportes de la interfaz social y las interfaces de conocimiento trabajadas en la Sociología del Desarrollo: Una perspectiva centrada en el actor por N.Long (2007). Básicamente, se procuran aplicar con técnicas cualitativas, elementos clave de una perspectiva de interfaz: "la interfaz como una entidad organizada de relaciones e intencionalidades entrelazadas, la interfaz como un sitio para el conflicto, la incompatibilidad y la negociación, la interfaz y el choque de paradigmas culturales, la centralidad de los procesos de conocimiento, el poder como resultado de luchas por los significados y relaciones estratégicas, la interfaz como compuesta de discursos múltiples, y la interfaz y la intervención planeada." (LoNG, 2007:142-148). En la práctica, y traducción mediante, esta teoría se trabaja con los actores, buscando en qué medida, los planteos de Long, contribuyen a entender y hacer más virtuosos los procesos con Inteligencia Territorial. En el caso de un OT con IT, el proceso 
refiere a la organización territorial y a su paso gradual al ordenamiento territorial, tarea que trabajamos con el Método Territorii, como veremos a continuación, los lugares refieren a micro-espacios entendidos y explicados de la manera más integral posible, como lo aplicamos con el Método Stlocus, mientras que los actores de las cuatro patas de la mesa, se trabajan con un cuestionario hecho con los actores y luego ejecutado con el Método Catalyse, con SPSS o bien con una encuesta.

La investigación-acción participativa, trabajada por Orlando Fals Borda, una autoridad en el tema en América Latina, Anglosajona y Europa, es una valiosa alternativa para generar un diálogo entre Teorías Sociales y de la Transformación. Al referirse al problema de cómo investigar la realidad para transformarla, FALs BoRDA (1986:15) plantea cuatro bases gnoseológicas que, en resumen, refieren al problema de la relación entre el pensar y el ser, o la sensación y lo físico, la diferencia entre lo conocido y lo que todavía no se conoce, la relación entre el pensar y el actuar, con una actividad real a la que se adviene por la práctica y al problema de la relación entre forma y contenido que también se resuelve por la práctica y no sólo por el comportamiento intuitivo o contemplativo. De allí que la teoría no pueda separarse de la práctica, ni el sujeto del objeto. ${ }^{5}$ En una dirección semejante, Maritza Montero plantea tres principios fundamentales de la psicología comunitaria: “...la autogestión de los sujetos que constituyen su area de estudio, el centro de poder cae en la comunidad, y la unión imprescindible entre teoría y praxis. (Se trata de...) una psicología de la acción para la transformación,

${ }^{5}$ Fals Borda, remitiendo a los ricos debates en el tema de la investigación-acción en el marco de un nuevo paradigma científico, escribe “...en la investigación participativa se combinan por lo menos dos elementos observables que la deslindan de otras formas de trabajo científico o investigativo: a) una estructura valorativa o ideológica con actitudes críticas relacionadas con el conocimiento y su utilización, el contexto social y patrones culturales en vías o en necesidad de mejoramiento y cambio; b) una batería de técnicas de encuesta multidisciplinarias combinables, derivadas de una sola lógica inmanente de investigación científica y de una epistemología holística o extensa. En consecuencia, la investigación participativa puede definirse como un método de estudio y acción que va al paso con una filosofía altruista de la vida para obtener resultados útiles y confiables en el mejoramiento de situaciones colectivas, sobre todo para las clases populares. Reclama que el investigador o investigadora base sus observaciones en la convivencia con las comunidades, de las que también obtiene conocimientos válidos. Es inter o multidisciplinaria y aplicable en continuos que van de lo micro a lo macro de universos estudiados (de grupos a comunidades y sociedades grandes), pero siempre sin perder el compromiso existencial con la filosofía vital del cambio que la caracteriza." (FALS BoRDA, 2009:319-320) Asimismo, el autor ofrece notables aportes en una decena de aspectos: Ciencia y realidad, Sobre la constatación del conocimiento, Sobre la realidad objetiva, Sobre los conceptos, Sobre la ciencia social crítica, La praxis y el conocimiento, Saber popular y acción política, Sobre el sentido común, Sobre la ciencia del proletariado y Sobre el sujeto y objeto del conocimiento. (FALs BordA, 1986:11-57).

Polígonos. Revista de Geografía, 26 (2014); 181-222 
en la cual investigadores y sujetos están del mismo lado en la relación de estudio, pues ambos forman parte de la misma situación." (MONTERO, 1984:398-399) ${ }^{6}$

\section{II.2.c. Teorías de la Transformación}

Subyacen y emergen a estos planteos perspectivas de transformación social y de generación de situaciones superadoras de contextos dominantes de procesos hegemónicos que conviven de manera compleja y conflictiva con otros elementos reales y persistentes de la práctica: la contrahegemonía y la hegemonía alternativa en R.Williams (1980). En un nivel más operativo investigamos y trabajamos en: a) cinco tipos de transformaciones: en conciencias, en espiritus, en miradas, en acciones y en objetos; b) cuatro planos de la transformación: en los individuos (en su interior), sociales (en el relacionamiento con los demás), territoriales/ambientales (en la adopción de conductas sustentables al medio ambiente) y decisionales (en la incidencia compartida en las tomas de decsiones); y c) la co-construcción de agendas entre las "cuatro patas de la mesa" -actores comunitarios, políticos, económicos y científicos- integradas por micro-acuerdos, micro-disensos, micro-acciones, micro-logros, micro-fracasos y micro-transformaciones en Bozzano $(2009,2012,2013 b)$ Estas manera de hacer ciencia se articulan básicamente con los aportes de la Epistemología del Sur en Boaventura de Sousa Santos (2009) y de la Ciencia Social Emancipatoria en Erik Olin Wright (2010). De de Sousa incorporamos principalmente sus tres premisas en la Epistemología del Sur, así como la ecología de saberes, el conocimiento-emancipación y el conocimiento-regulación, estos últimos con base en Max Weber; el primero, relacionado con la estética, el conocimiento y la ética, mientras que el segundo, con el Estado, el mercado y la comunidad; sus tres premisas en resumen plantean (1) las cuestiones de la justicia social global en un contexto de justicia cognitiva global, (2) en un escenario de perdurabilidad y permanencia del capitalismo y el colonialismo, y (3) trabajando en prácticas de conocimiento que permitan intensificar la voluntad de transformación social. Incorporamos la justicia ambiental a la justicia social. De Wright incorporamos las tres etapas en la construcción de una Ciencia Social Emancipatoria: el diagnóstico crítico, la imaginación de alternativas y el desarrollo de una teoría de la Transformación, así como con las tres formas de poder: capitalismo, socialismo y estatismo.

${ }^{6}$ El objeto de la psicología comunitaria puede resumirse en dos planos articulados, tanto “...el poder y control sobre las circunstancias de vida por parte de las personas que integran las comunidades, así como el cambio social.” En resumen “...la comunidad como ámbito y sujeto del quehacer psicosocial comunitario...(mientras que) el trazado de las líneas de transformación se hace desde la propia comunidad y, sobre todo, desde las aspiraciones, los deseos y las necesidades de la comunidad" (MONTERo,2004:77-78) 


\section{II.3. Un intento de aplicación de las teorías: los métodos Territorii y Stlocus.}

Se investiga y progresa hace más de una década, con cada aplicación, en versiones mejoradas de los Métodos Territorii, en Bozzano (2000, 2009, 2012 , 2013b, 2014) y Stlocus en Bozzano y Resa (2009) y Bozzano (2009, 2012, 2014) combinados con una caja de herramientas sociales y espaciales para que contribuyan a producir en cada caso un OT con IT que sea no sólo más viable y factible, sino que represente el pensar y el sentir de la gente. Territorii y Stlocus son dos métodos de aplicación flexible con una visión integral de los territorios y los lugares respectivamente. En sus últimas versiones de 2013, incorporan en mayor medida la participación de actores comunitarios, políticos, económicos y científico-técnicos. Por qué los nombres? Territorii en latín significa la tierra de algo y de alguien, Stlocus en latín antiguo significa el lugar de algo y de alguien; en ambos casos hay una relación entre sociedad y naturaleza, identidades comunitarias e identidades territoriales. Ambos son métodos con base científica para incorporar en Procesos de Intervención y Transformación con Inteligencia Territorial, vale decir que no aplican sólo a objetos de estudio, sino a objetos de intervención y de transformación, cada uno de ellos supone una triangulación ascendente: en resumen procesos, lugares y actores (estudio), ideas en proyectos, espacios banales en territorios sustentables y perosnas en sujetos (intervención) e identidades, necesidades y sueños (transformación).

Territorii se hace con tres objetivos centrales: 1) conocer y reconocer el territorio mediante el tránsito de ocho momentos: territorios reales, vividos, pasados, legales, pensados, posibles, concertados e inteligentes; 2) dar a conocer proyectos e iniciativas existentes, instaladas y nacientes, referidos a todos los planos de la vida, por lo general insuficientemente conocidos por la sociedad; y 3) generar un espacio de formación de la comunidad, orientado a aprender a concebir, formular y concretar proyectos con resultados palpables por la gente insertos en una problemática más amplia que la de cada proyecto. El método aplica los ocho conceptos mencionados que coinciden con ocho fases, que resumen, en buena medida, instancias y lecturas descriptivas, perceptivas, históricas, prescriptivas, explicativas, propositivas, inteligentes y transformadoras de los territorios.

Stlocus tiene dos objetivos centrales: 1) definir científicamente con aporte de las comunidades locales cada uno de los lugares en la microescala, en términos de patrones de ocupación y apropiación territorial, con 7 macro-variables o conceptos operacionales y más de 30 variables; y 2) conocer mejor los problemas y las soluciones a trabajar con la gente en cada lugar. El método parte de tres conceptos con grados de abstracción decreciente: territorio, lugar y lógica de pro- 
ducción de espacio; luego se va "aterrizando" con siete conceptos operacionales: territorialidades, vocaciones, racionalidades, procesos, tendencias, actores y espacialidades, las cuales a su vez se hacen operativas en variables: territorialidades urbanas, periurbanas, rurales y naturales, vocaciones centrales, residenciales y otras, racionalidades sociales, económicas y ambientales, procesos sinérgicos y conflictivos, tendencias de valorización pública, social y económica, vulnerabilidad, accesibilidad, conectividad y otras, actores públicos, comunitarios, económicos y otros, espacialidades absolutas, relativas y relacionales.

\section{II.4. La Inteligencia Territorial y una metáfora}

La IT nace en la Europa de la crisis del petróleo, promueve una transición socio-ecológica y prácticas de investigación donde el objeto es el desarrollo sustentable de los territorios y el sujeto es la comunidad territorial.(GIRARDOT;2009:13-14) En América Latina es más reciente: coincidente con los planteos de su creador J.J.GiRARDOT, en las numerosas Universidades hoy participantes de la INTI Network se pone en mayor medida el hincapié en Procesos de Intervención y Transformación con Inteligencia Territorial básicamente con cuatro cometidos: producir transformaciones en cuerpo y alma, comunitarias, ambientalesterritoriales y decisionales. Cómo se traduce esto en la práctica? Significa que cada individuo tenga la oportunidad de transitar un proceso en el que sea sujeto de su autoconocimiento, que promueva sus identidades y sus sueños (1); que ejercite el relacionamiento con todas las "patas de la mesa", que en el disenso valore la discusión, la mediación y los acuerdos con los demás (2); que, conociéndolas, adopte conductas mas cuidadosas del ambiente y sus territorios, sobre todo en una gran proporción de la Humanidad que desconoce los problemas que tenemos (3), y que tome conciencia que si las decisiones no las toman los otros, sino que las tomamos junto con los otros, el poder del conocimiento podrá construir un nuevo poder donde los tres poderes que hoy dominan el mundo -político, económico y mass media- y así se podrán incorporar el poder social y el poder del conocimiento para hacer esta vida más llevadera, austera y feliz.

En 2009 cuando intentamos interpretar cómo podía entenderse y aplicarse la IT, inexistente en ese momento en América Latina, proponíamos la imagen de una metáfora, que denominamos de las "cuatro patas de la mesa de la IT" dentro de la Perspectiva EIDT en Entendimiento, Inteligencia y Desarrollo Territorial (Bozzano, Karol y Cirio, 2009:4). Desde aquel entonces, esta metáfora es la primera imagen que compartimos con los sujetos de cada objeto, cuando comenzamos a trabajar con ellos. Téoricamente, en la metáfora de la figura 2, las patas se sustentan en el reconocimiento de los tres pilares de la regulación en Max Weber: el Estado, la comunidad y el mercado, su reinterpretación en de Sousa Santos, 
combinado éste a la innovación de adicionar una cuarta componente relacionada con un conocimiento científico alternativo, más útil a la Humanidad y al Planeta, en articulación con los pilares de la regulación. La tabla de la mesa refiere al territorio, entendido como lo definimos en el ítem precedente; mientras que cada torta con sus capas, refiere a cada proyecto con las fases de cada proceso: en este trabajo el Código de Ordenamiento Urbano y Territorial representó una gran torta, cuya elaboración duró cuatro años. Nuestra posición es que, de muy diversa manera, el poder del conocimiento a través de un paradigma emergente podrá renovar las difíciles relaciones en el Planeta y la Humanidad: se trata de una cuarta pata que podrá dar más y mejor sostén a la tabla de la mesa: el territorio. Los colores de fondo refieren a las perspectivas y abordajes de la IT latinoamericana, en orden ascendente: sujetos, objetos o proyectos, herramientas y proyección o transformación. Asimismo, cada pata se integra de astillas muy diversas, unas ligadas a transformaciones virtuosas, otras a transformaciones viciosas; en general estas astillas se presentan entremezcladas en cada realidad donde se despliega la vida en común.

Figura 2. La metáfora de la Inteligencia Territorial en América Latina

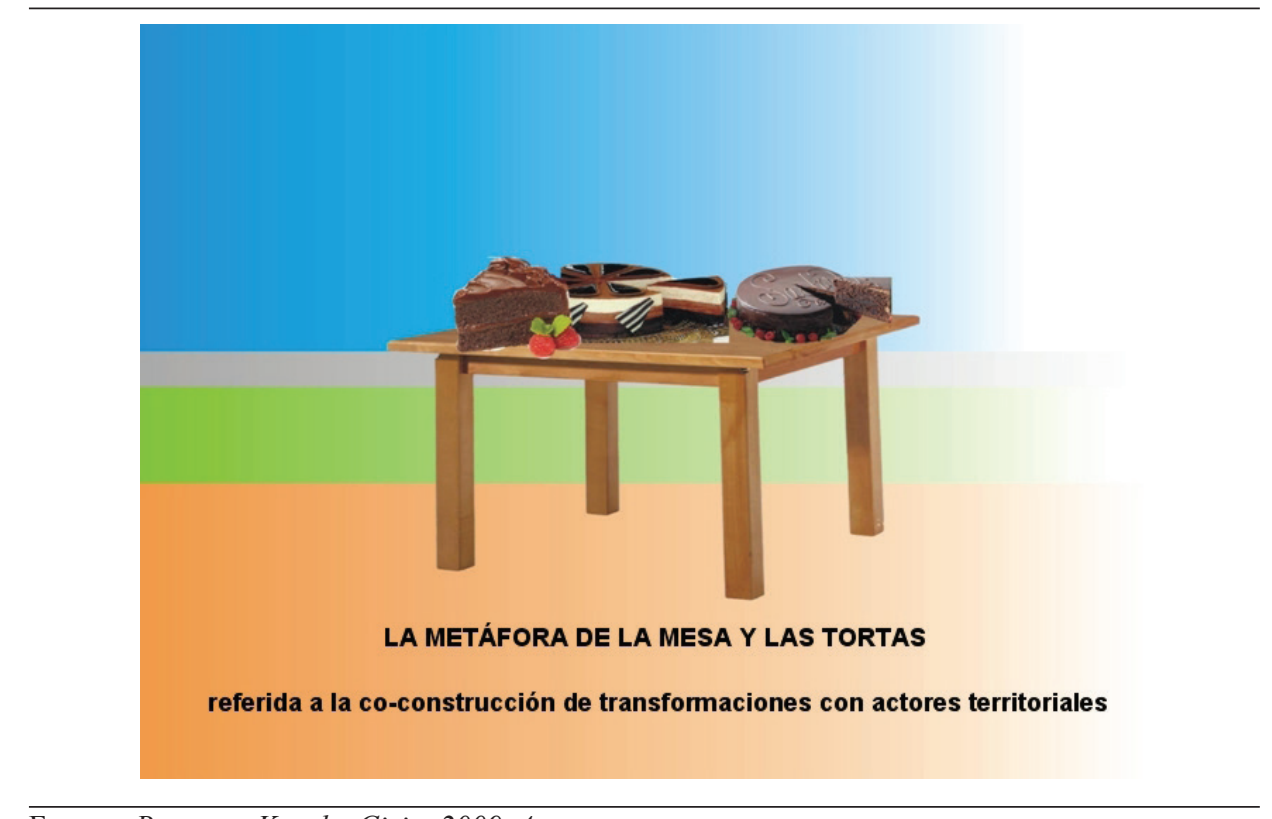

FUENTE: Bozzano, Karol y Cirio, 2009, 4

A escasos cinco años de su creación hemos reconocido once líneas de investigación-acción producto de los aportes realizados desde 39 Universidades 
pertenecientes a nueve países latinoamericanos: 1-Planificación, ordenamiento y gestión territorial en clave de IT, 2-Turismo sostenible, ambiente, cultura y empleo en clave de IT, 3-Producciones familiares, agroecología y empleo en clave de IT, 4-Educación, sensibilización, concientización y capacitación en clave de IT, 5-Niños, jóvenes, tiempo libre y trabajo en clave de IT, 6-Proyectos sociales y culturales en clave de IT, 7-Protección y respeto del ambiente en clave de IT, 8-Proyectos urbanos y barriales en clave de IT, 9-Proyectos de desarrollo rural en clave de IT, 10-Proyectos institucionales en clave de IT y 11-Proyectos empresarios en clave de IT. Más allá de disciplinas, objetos y parcelas del saber, en las once líneas podemos investigar promoviendo los cuatro cometidos de la transformación mencionados con las otras "patas de la mesa".

\section{INICIATIVAS Y MÉTODOS EN LA PLATA, ARGENTINA Y MI- NAS, URUGUAY}

\section{III.1 Ordenamiento territorial en La Plata 1997-2001}

III.1.a. Antecedentes: características, maduración, investigación y participación

La Plata es un municipio de 649.613 habitantes (2010) y $924 \mathrm{~km} 2$. Es la capital de la Provincia de Buenos Aires, el primer estado argentino, y está situada a $56 \mathrm{~km}$ de la Ciudad de Buenos Aires. Junto con EnsenadA y Berisso (787.294 habitantes, 2010) forma el denominado Gran La Plata: es la sexta aglomeración urbana argentina, después de Buenos Aires, Córdoba, Rosario, Mendoza y Tucumán. La Plata es la ciudad más universitaria de Argentina: uno de cada seis habitantes es estudiante universitario; también es un importante centro de servicios culturales, sanitarios, educativos y financieros, concentra en su periurbano el cinturón flori-hortícola más importante del país, mientras que en Ensenada y Berisso se encuentra el polo petroquímico más grande de Argentina.

Luego de casi 20 años sin cambios en la regulación y fuertes transformaciones urbanas y territoriales, el gobierno municipal decide actualizar su código de ordenamiento urbano y territorial, vigente desde 1979. Es así que desde 1997 con el aporte de la universidad, colegios y consejos profesionales elabora un nuevo proyecto que es aprobado en Diciembre de 2000; y que se aplicó durante más de una década. En 2011 el código tuvo una modificación que significó un retraso importante en los logros obtenidos. El 2 de abril de 2013, 350 mil de los 800 mil habitantes del Gran La Plata fuimos afectados por una inundación sin prece- 
dentes: en pocas horas llovieron $392 \mathrm{~mm}$ y el ordenamiento territorial, las obras hidráulicas y de seguridad industrial y la escasa trayectoria en planes de contingencia ciudadana dejaron traslucir notables insuficiencias y conflictos.

El Proyecto de Ordenanza de Ordenamiento Territorial aprobado en 2000 es resultado de un proceso de trabajo, investigación, maduración y ajuste, con numerosos aportes. Entre las nutrientes del Proyecto se encuentran los siguientes "Estudios de base y aportes a la propuesta del Código: I - Ideas para un Nuevo Régimen Legal de Planeamiento (libro) Dirección de Planeamiento, Municipalidad de La Plata, 1995; II - Estudio Exploratorio de Ventajas Comparativas de la Región Capital de la Provincia de Buenos Aires. PNUD Arg 95/013, Ministerio de Gobierno, Prov.Buenos Aires, 1998; III - Bases Estratégicas para el Desarrollo Sustentable de La Plata; Municipalidad de La Plata. Coordinación: Fundación CEPA, 1999; IV - Patrones territoriales: Estudio de base para un código de ordenamiento territorial, Premio Anual en el rubro Investigaciones Urbanas del Colegio de Arquitectos de Prov.de Buenos Aires. Investigación realizada entre 1995 y 1999 por Dirección de Planeamiento, con aporte de Convenio con Depto. de Geografia de la UNLP en 1996. (Este aporte es el que luego se denominaría Método Stlocus); V - Los territorios de la reestructuración industrial en la Región Metropolitana de Buenos Aires. Capítulo sobre La Plata y Conclusiones. Tesis doctoral, Universidad de la Sorbona Paris III, 1999; VI - Elementos de Diagnóstico presentados al COUT; VII - Informes, opiniones y dictamenes de las instituciones del Cout sobre temas generales y temas sectoriales; 1997 - 2000."(MLP, 2000:8) Fue clave el largo camino de gestación y maduración de la ordenanza que se fue plasmando en la interacción con diversos interlocutores; así, la estrategia de trabajo permitió ir incorporando mecanismos de participación y logrando sucesivos acuerdos.

III.1.b. Territorii, una manera de compartir el proceso con las "cuatro patas de la mesa"

La construcción del proceso de ordenamiento territorial en La Plata fue, junto a otros tres proyectos desarrollados esos años, el pacto fundacional del Método Territorii. En las reuniones mantenidas todos los miércoles en el COUT, en el trabajo con la treintena de personas que participaron en la elaboración del proyecto, en el convenio con la Universidad y en interacción con otros actores el modus operandi fue decisiva nutriente para incorporar instancias descriptivas, perceptivas, históricas, normativas, explicativas, proyectuales, concertadas y factibles, lo cual fue clave para reconocer territorios reales, vividos, pasados, legales, pensados, posibles, concertados e inteligentes en personas de las "cuatro patas de la mesa". Al compartir temáticas y problemáticas con un mismo lengua- 
je, al momento que, para entendernos mejor se hacía un esfuerzo de traducción (DE Sousa, 2009:143), se contribuía a generar un espacio de formación de la comunidad, orientado a aprender a concebir, formular y concretar proyectos con resultados palpables por la gente insertos en una problemática más amplia que la del proyecto de referencia. Se trataban temáticas generales (la industria, la valorización nmobiliartia, la degradación ambiental, etc), intermedias y puntuales, se refería al diagnóstico, los escenarios posibles, sus fundamentos, los pro y los contra, y una gran variedad de aspectos con una gran heterogeneidad de actores.

Hoy, a quince años de aquel proceso, se presenta en apretada síntesis una interpretación de los ocho momentos de Territorii en dicho proceso. Los territorios reales se refieren, entre otros, a los usos reales del suelo por parcela rural y manzana, la densidad de población, el factor de ocupación del suelo construido real por manzana, el valor del suelo, la localización de comercios, servicios e industrias, las necesidades básicas insatisfechas, la aptitud agrícola del suelo, las redes de infraestructuras y servicios. Los territorios vividos se refieren, entre otros, a percepciones positivas y negativas del centro, los barrios y otros lugares, imágenes de íconos urbanos a promover en un nuevo código, problemas derivados de la aplicación del código anterior por parte de vecinos o familias afectadas. Los territorios pasados refieren a las fases del proceso de organización territorial de los espacios más salientes: la ciudad, el suburbio, el periurbano y el medio rural; también refieren a la valorización patrimonial arquitectónica de la Ciudad de La Plata. Los territorios legales refieren a las áreas urbanas, complementarias y rurales -y sus zonas respectivas- de la ordenanza municipal de adecuación a la ley provincial de ordenamiento territorial y usos del suelo, con sus indicadores urbanísticos y territoriales. Los territorios pensados refieren a los patrones territoriales o lugares: el resultado fue la identificación por lote de 44 lugares urbanos, periurbanos y rurales en la microescala con atributos sociales, económicos, físicos y otros comunes; así como a las tendencias del proceso de organización territorial por lugares: creación, expansión, consolidación, fortalecimiento, estancamiento y retracción. Los territorios posibles refieren a un código urbano y territorial factible y viable que incorpore los aspectos más sustentables emergentes de cada uno de los lugares o patrones territoriales, y de las tendencias del proceso de organización territorial en la ciudad, el suburbio, el periurbano y el espacio rural. Los territorios concertados refieren a una agenda de reuniones semanales en el COUT Consejo de Ordenamiento Urbano y Territorial durante más de tres años que tuvieron como resultado un territorio legalmente concertado, aprobado luego por el Concejo Deliberante, el Poder Ejecutivo Municipal y por la autoridad provincial competente. Los territorios inteligentes refieren a un nuevo código urbano y territorial funcionando, dando respuestas a demandas y problemas que tenía el código anterior, en materia de promoción de la calidad urbana, periurbana 
y rural de los lugares, y de las restricciones de usos, subdivisiones y otros indicadores. Se llegó a esta instancia, pero años después el código fue modificado, perdiendo parte de su esencia.

III.1.c. Los patrones territoriales, antecedente del actual Método Stlocus

Desde 1988 veníamos realizando intentos por definir metodológicamente lugares en la micro-escala, procurando superar visiones preferentemente descriptivas del estilo de los mapas de usos reales del suelo. Entre 1995 y 1999 con Sergio Resa y un grupo de treinta y nueve personas ${ }^{7}$ se dio un paso importante con una investigación denominada "Patrones territoriales: Estudio de base para un código de ordenamiento territorial.

En cinco años de trabajo la investigación fue evolucionando desde lógicas basadas preferentemente en la priorización de cuatro espacialidades -centrales, residenciales, periurbanas y rurales- hacia otras espacialidades apoyadas en la actividades dominantes de cada lugar: centrales, residenciales y productivas. Combinaciones sucesivas de decenas de configuraciones espaciales -en mapas temáticos muy detallados- nos permitieron ir avanzando gradualmente de lo que denominamos prepatrones hasta finalmente llegar a los patrones territoriales. En apretado resumen lo que fue, entre 1995 y 1999, la aplicación de la versión 3 del actual Método Stlocus se ejecutó en las siguientes etapas: 1) Ambitos y variables por espacialidad, 2) Prepatrón territorial descriptivo, 3) Ambitos y variables por actividad, 4) Articulación escalar micro-meso-macro y 5) Patrón territorial explicativo. Finalmente se propusieron 44 patrones territoriales o lugares que cubrieron en la microescala -por parcela rural y manzana- las 94.200 hectáreas del Partido de La Plata. El trabajo se fue exponiendo, compartiendo, co-construyendo y mejorando durante muchas sesiones del COUT Consejo de Ordenamiento Urbano y Territorial donde cada miércoles partcipaban Colegios Profesionales (Arquitectura e Ingeniería), la Universidad (Arquitectura y Geografía) y la Cámara Argentina de la Construcción.

${ }^{7}$ Por Planeamiento Municipal participaron: S.Resa (director), L.Bosisi, G.Curtit, P.Pintos, C.Kochanowsky, H.Olivera y S.Moscardi. Por Geografía de la UNLP participaron: H.Bozzano (director), C.Carut, L.Lértora, V.Pohl Schnake, S.Fernández, F.Anuchnik, D.Arturi, F.Gliemmo, G.Losano, S.Perdoni, A.Pérez Ballari, S.Marega y A.Moncaglieri. En algunas etapas, por Planeamiento Municipal participaron: C.Foulkes, A.Sgroi, A.Kauffer, E.Landaeta, N.Lamberti, H.Martino, O.Minervini, P.Mosquera, C.Porotelli, S.Redondo, A.Robiglio, D.Souto, P.Strelzik, C.Urrera, y en la última etapa: G.Rozas, V.Vázquez, G.Barakdjian, M.Tellería y C.Ybarra. 


\section{Etapa 1: Ambitos y variables por espacialidad.}

1.a) Ámbitos de Centralidad. Las variables seleccionadas para determinar prepatrones y luego patrones de centralidad fueron clasificadas según su función dominante; algunas preferentemente "económicas" (1 a 7) y otras más "sociales" (8 a 14). En resumen fueron: 1-Bancaria y Financiera; 2-Servicios centrales (clínicas, consultorios, colegios y consejos profesionales, gestorías, estudios); 3-Comercio complementario y servicios (no incluye comercio barrial); 4-Comercio y servicios barriales (en áreas suburbanas); 5-Comercio mayorista; 6-Talleres, grandes depósitos; 7-Industria; 8-Transporte (Centros y "mini-centros"de transferencia); 9- Administración Pública; 10-Sanitaria (incluye Hospitales y grandes Institutos privados); 11-Universitaria y Terciaria; 12-Cultural; 13-Recreativo y Deportivo; y 14-Enseñanza Media (según rango) y Primaria (en el suburbio).

1.b) Ámbitos Urbano-Residenciales. Variables: 1-FOS-Factor de ocupación del suelo; 2-Densidad neta de Población; 3-Indice combinado de Nivel de Instrucción y Nivel de Ingresos; 4-Valor de la Tierra (mercado inmobiliario); 5-Transporte (tiempo de acceso al servicio); 6-Cobertura de Servicios (Índice combinado de siete servicios); 7-Usos no residenciales (según cuatro lógicas de ocupación); 8-FOT (Factor de Ocupación Total); 9-“Tipología edilicia barrial”; 10-Situación dominial (asentamientos, villas y ocupación de lotes); 11-Organizaciones intermedias; y 12Red vial jerarquizada de pavimentos. Cada variable fue objeto de clasificación en cinco intervalos de clase con el propósito de operacionalizar correlaciones posteriores; en cada caso los valores son: bajo, medio-bajo, medio, medio-alto y alto. Se agregó como variable compleja, una investigación sobre problemas ambientales urbanos adaptada de una Metodología del Comité Mab/Argentina..

1.c) Ámbitos Periurbanos. Este concepto refiere a cuatro formas de ocupación: Producciones primario-intensivas, segunda residencia, ocio y esparcimiento, subcentros y pequeñas localidades, y economía urbana (industrias, grandes talleres, depósitos y comercio mayorista). La variable principal es: 1-Uso del suelo -en catorce categorías por parcela rural y manzana- y las variables secundarias son: 2-Relieve y áreas inundables; 3-Red de vías de comunicación; 4-Envolventes de valorización del suelo; 5-Variación del área hortícola 1984/1992 y 1992/1996; 6-"Cinturón hortícola no hortícola"; 7-Organización de ámbitos periurbanos (Ejido de Chacras, Quintas y Hornos, colonias, etc); 8-Subcentros y localidades; 9-Transporte público y 10-Ambitos con recursos naturales degradados.

1.d) Ámbitos Rurales. Variables: 1-Aptitud del suelo, 2-Tamaño de explotaciones y 3-Uso del suelo. Este patrón es modificado parcialmente en algunos lugares por dos factores: la presencia de áreas inundables y ejes viales regionales que atraviesan el ámbito produciendo variaciones en el precio del suelo. 
1.e) Otros ámbitos. Aquí es posible observar lógicas y tendencias de ocupación y de apropiación claramente diferenciadas del resto, básicamente a una serie de usos específicos, en particular grandes equipamientos. En esta etapa la mayoría de los mapas temáticos fue objeto de elaboración propia por parte del equipo de 39 integrantes, lo cual insumió años de trabajo; se respetó en cada mapa el Método Portulano (Bozzano, 2009a), método cartográfico consistente en una secuencia de once pasos apoyados en la Semiología Gráfica de Jacques Bertin.

Etapa 2: Prepatrón territorial descriptivo. Numerosos y trabajosos análisis y correlaciones espaciales referidas a dimensiones sociales, económicas, fisicoconstruidas y fisico-naturales realizadas entre los mapas de espacialidades centrales, urbano-residenciales y las demás, contribuyeron a identificar los primeros patrones territoriales. El prepatrón territorial descriptivo es el ámbito territorial en la microescala en el que se reconoce claramente la presencia de particulares combinaciones de clases de las variables. A estos "pre-patrones", hoy los denominamos "pre-lugares" o "lugares preliminares". En esta etapa identificamos 12 prepatrones de centralidad, 14 urbano-residenciales y 11 periurbanos. A título ilustrativo algunos de estos últimos fueron: periurbano especulativo o "pre-urbano", periurbano de baja productividad y alto valor de la tierra, productivo fuerte de colonias, productivo fuerte no planificado, productivo en retroceso y grandes equipamientos.

Etapa 3: Ambitos y variables por actividad. Luego de definidos estos prepatrones fuimos observando el peso que tenían la naturaleza misma de las lógicas de ocupación dominantes; fundamentalmente estas lógicas no respondían en primera instancia a espacialidades sino a la esencia misma de los procesos que permitían entenderlas. Este fue el motivo por el cual optamos finalmente por clasificar los patrones según este criterio. Al cabo de muchas idas y venidas los prepatrones se fueron acercando a algo que siempre con alguna duda llamamos finalmente patrones territoriales. A partir de este supuesto fuimos estableciendo ámbitos centrales, residenciales, productivos y otros sin actividades dominantes. Esto significaba que por ejemplo detectábamos en esta instancia un ámbito productivo -hortícola, industrial o ganadero- que previamente habíamos definido como prepatron periurbano, residencial urbano o rural; o bien encontrábamos en este momento de la investigación un ámbito residencial de casas de fin de semana que a priori era un prepatrón periurbano alejado de la ciudad. Una vez determinados los prepatrones y definidos a priori estos ámbitos se establecieron criterios de interpretación analíticos para cada ámbito. En el caso de los ámbitos centrales las variables definidas para interpretar cada ámbito fueron las siguientes: 1-peso o nivel de centra- 
lidad, aquí se incluye su influencia o alcance regional, 2-diversidad de funciones, 3-perfil, 4-logica de ocupación dominante, y 5-trayectoria, identidad y grado de consolidación de cada centralidad. En el caso de los ámbitos residenciales las variables definidas para interpretar cada ámbito fueron las siguientes: 1-instancias del proceso de urbanización: creación, expansión, consolidación y estancamiento, 2-transformacion de ámbitos residenciales, y 3-morfologia urbana. En el caso de los ámbitos productivos las variables definidas para interpretar cada ámbito fueron las siguientes: 1-grado de consolidación, 2-indicadores de productividad, 3 -incidencia en la valorización del suelo y 4-condicionantes físicas antropicas y naturales. Hubo otros casos en los cuales los ámbitos no registraban actividades dominantes; aquí diferenciamos ámbitos mixtos de otros sin actividades. Este análisis no fue objeto de mapeo detallado como ocurriera con la etapa 1, sino que coinsistió básicamente en un cruce de los resultados de la etapa 2 con una interptretación analítica y combinada de cada una de las variables de la etapa 3.

Etapa 4: Articulación escalar micro-meso-macro. Si bien desde el inicio del trabajo se investigó en el proceso de organización territorial (escala macro) y en sus lógicas y tendencias de ocupación y de apropiación territorial (escala meso), la tarea de articulación teórica y empírica con la micro-escala (los patrones territoriales) se realizó preferentemente en esta cuarta etapa. Conociendo mejor los resultados en la micro-escala se pudieron hilvanar e inscribir en mejores condiciones a nivel urbano y regional los resultados de la investigación. Máxime que La Plata integra una de las principales regiones metropolitanas de América Latina: Buenos Aires, siendo su segundo centro en importancia. La organización territorial supone la explicación de un ámbito espacial -no menor a la escala regional- a partir de procesos específicos, reconociendo a su vez en éstos políticas, estrategias, intervenciones u otras acciones. La organización territorial se refiere al menos a cinco instancias de un proceso: creación, expansión, consolidación, fortalecimiento, estancamiento y retracción. Asimismo, una forma de identificar y explicar la presencia de variantes en el proceso de organización territorial a nivel urbano es mediante el reconocimiento de lo que denominamos lógicas y tendencias de ocupación y de apropiación territorial dominantes. Las lógicas y tendencias de ocupación están relacionadas con indicadores físicos naturales y construidos. Las lógicas y tendencias de apropiación en cambio están emparentadas con la relación individuo-sociedad y con la relación espacio privado- espacio público. Ambas lógicas y tendencias son criterios explicativos de los patrones, contribuyendo en este sentido a sintetizarlos, así como a entender el lugar que ocupan dentro del proceso de organización territorial. A título ilustrativo algunas 
de las seis tendencias analizadas fueron: principales áreas de inversión pública en servicios urbanos y principales áreas de construcción de viviendas.

Etapa 5: Patrón territorial explicativo. Es el patrón territorial con el que se concluyó la investigación. Se trata de un ámbito territorial en la microescala que surge de la sobreconstrucción entre la instancia previa -patrón descriptivo- y una serie de criterios de interpretación referidos a instancias del proceso de organización territorial (creación, expansión, consolidación, estancamiento y retracción), así como a lógicas y tendencias de ocupación y de apropiación particulares. El proceso de construcción teórico-metodológica para aplicarlo a un código de ordenamiento territorial se cierra con la presentación del proyecto al Concejo Deliberante en Abril de 1999. En síntesis los 44 patrones territoriales fueron:

Patrones de centralidad: 1 Microcentro institucional (administrativo, financiero, universitario, cultural), 2 Microcentro comercial y de servicios calificados, 3 Centro, 4 Derrame del centro, 5 Subcentro de primer rango, 6 Subcentro de segundo rango, 7 Protocentro, 8 Corredor de acceso principal de primer rango, 9 Corredor de acceso principal de segundo rango, 10 Corredor barrial de comercio y servicios, 11 Centralidad de origen asistencial, 12 Centralidad de origen universitario y 13 Centralidad de origen comercial. Patrones residenciales: 14 Residencial central, 15 Barrial consolidado del casco, 16 Barrial consolidado del desborde del casco, 17 Barrial en consolidación del desborde sur del casco, 18 Barrial en consolidación del desborde oeste del casco, 19 Barrial en expansión del desborde del casco, 20 Cascos urbanos del eje norte, 21 Residencial consolidado del eje norte, 22 Residencial en consolidación del eje norte, 23 Mixto de articulación con parcelario urbano y rural, 24 Villas-miseria y asentamientos precarios, 25 Barrios periféricos poco consolidados en expansión, 26 Loteos periféricos con baja ocupación, 27 Loteos urbanos baldíos dominantes, 28 Intersticial de baldíos urbanos y rurales (incluye bordes urbanos), 29 Centros de servicios rurales y urbanos y y 30 Periurbano residencial y segunda residencia de baja densidad. Patrones productivos: 31 Industrial agrupado planificado con atractividad territorial, 32 Gran industria en medio suburbano o periurbano, 33 Flori-hortícola consolidado (incluye colonias y ámbitos no planificados), 34 Hortícola dominante "a campo" no consolidado, 35 Hortícola dominante de alto valor de la tierra (incluye horticultura en retroceso) y 36 Agropecuario pampeano. Otros patrones (ámbitos que no responden dominantemente a ninguna de las tres lógicas de ocupación: centrales, residenciales y productivas) 37 Mixto residencial, comercio mayorista, pequeña industria y depósitos, 38 Mixto de segunda residencia, esparcimiento, horticultura y baldíos urbanos y rurales, 39 Periurbano de parcelamiento rural subutilizado 
no consolidado como productivo ni residencial, 40 Periurbano con restricciones físicas por decapitación de suelos, 41 Periurbano con grandes restricciones por presencia de cavas y canteras, 42 . Grandes predios forestados y/o parquizados con valor paisajístico, 43 Grandes ámbitos con actividades recreativas y/o deportivas y 44 Grandes ámbitos con usos específicos: aeródromos, unidades militares, carcelarias. Se definen otros rasgos salientes cuya significación no permite definirlos como patrones particulares, sino como aspectos relevantes de cualquier patrón: a) ámbitos con valor arquitectónico, b) ámbitos inundables de máximo y medio riesgo hídrico, y c) ámbitos valorizados por ejes viales regionales.

Estos estudios e investigaciones sobre los patrones territoriales realizados desde 1995 permitieron entender la esencia de cada ámbito, de cada lugar, tarea muy significativa al momento de definir mecanismos regulatorios. La figura 2 presenta -a título ilustrativo- los 44 lugares o patrones territoriales que fueron trabajados en el COUT Consejo de Ordenamiento Urbano y Territorial para la puesta en marcha del Código de Ordenamiento Urbano y Territorial que finalmente se aprobó el 28 de Diciembre de 2000. En http://territoriosposibles.fahce.unlp.edu. ar clic en Método Stlocus se pueden consultar otros mapas temáticos con mayor detalle y referencias, resultado de nuestra investigación.

\section{III.1.d. Algunos resultados del proceso 1997-2000}

Los resultados aquí expuestos de manera muy sintética fueron trabajados en muchas de las sesiones semanales del COUT Consejo de Ordenamiento Urbano y Territorial del Partido de La Plata, creado por Ordenanza 8733/96, donde participaron la Dirección de Planeamiento de la Municipalidad como Secretaría Ejecutiva junto a seis instituciones: el Colegio de Ingenieros de la Provincia de Buenos Aires, el Colegio de Arquitectos de la Provincia, la Cámara Argentina de la Construcción, el Departamento de Geografía y la Facultad de Arquitectura, ambos de la Universidad Nacional de La Plata y el Consejo Profesional de Ciencias Naturales de la Provincia.

"Una de las fortalezas del COUT fue el nuevo poder que entre 1997 y 2010 se fue logrando mediante el ejercicio permanente de interacción -inexistente en La Plata hasta ese momento- trabajando con las diversas "patas de la mesa". La tabla de la mesa en el COUT estuvo representada por todos los lugares del territorio de La Plata donde se intervino en los cientos de actuaciones a lo largo de 12 años de gestión, mientras que las tortas refirieron a cada una de las actuaciones llevadas a cabo." (RESA y BozZANo, 2014:12) En 2010 el gobierno cerró el COUT. En cuanto a los planos de la transformación referidos en el trabajo, cada una de las personas que participaron del COUT representando a diversas "patas de la mesa" experimentaron sin ninguna duda, en mayor o menor grado, micro-transformaciones en los cuatro 
planos referidos, en particular aquellas personas que pudieron participar mas años a lo largo del proceso. Como partícipes del COUT reunión a reunión, miércoles a miércoles, durante los primeros siete años de su existencia, pudimos constatar lo que significó para cada uno de los participantes el compromiso de debatir, argumentar, fundamentar, intercambiar, discutir, disentir, negociar y acordar con personas representativas de diversas "patas de la mesa" en un gran número de temas. Cada miércoles se ponía cuerpo y alma, las calurosas y respetuosas discusiones daban lugar luego de cada sesión a encuentros de balances y catarsis entre los compañeros de trabajo. En definitiva ello produjo un ejercicio de triple aprendizaje: a relacionarnos en mejores condiciones con el otro, a ser más conscientes del cuidado del territorio y el ambiente, y a incidir en unas tomas de decisiones más compartidas entre los presentes.

Figura 2. Patrones territoriales 1999 en el Partido de La Plata

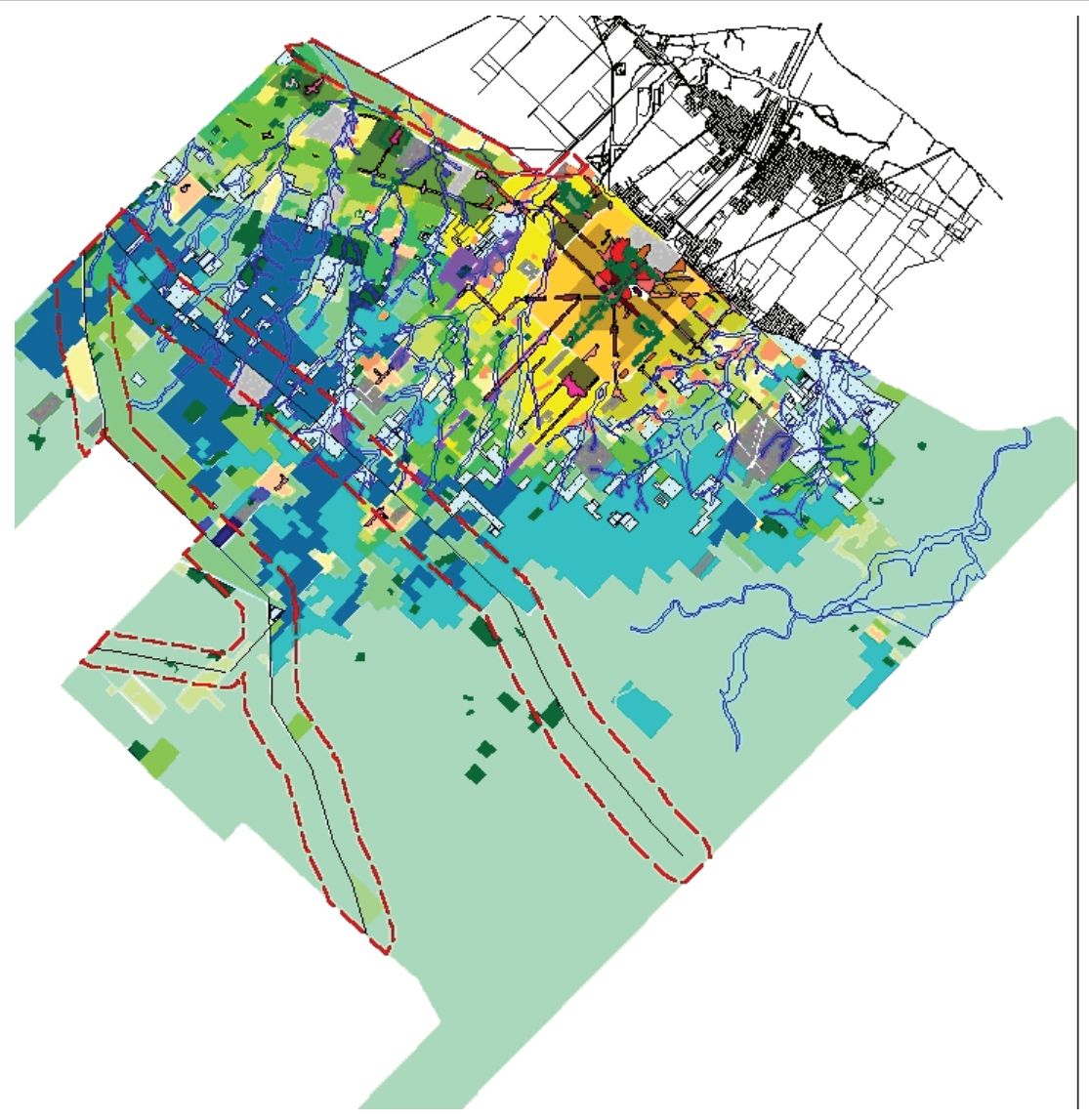

FuENTE: Municipalidad de La Plata, 2000, 79 


\section{III.2 Ordenamiento territorial en Minas 2012-2014}

\section{III.2.a. Características, antecedentes y trabajo reciente}

Minas es la capital de Lavalleja, uno de los 19 Departamentos de Uruguay. La ciudad tiene 38.446 habitantes (Censo Nacional de Población y Viviendas 2011) y está situada a $120 \mathrm{~km}$ de Montevideo y $77 \mathrm{~km}$ de Punta del Este; tiene un centro comercial, administrativo, turístico y de servicios, trece pequeños subcentros barriales, parques públicos de renombre nacional y más de treinta barrios distribuidos en torno a tres ejes de crecimiento y expansión urbana. Es conocida como la "capital de las sierras" del Uruguay: con alturas que oscilan entre 105 y 225 metros sobre el nivel del mar, relieve e hidrografía organizan ambientalmente un espacio urbano que ha respetado históricamente en general condiciones naturales y que se han considerado tanto en los escenarios deseables como en las normas y sus indicadores que regirán en las Zonas del Plan Local en vías de instrumentarse. En su periurbano (equivalente al suburbano de la ley $n^{\circ} 18308$ Ordenamiento Territorial y Desarrollo Sustentable) se encuentran cuatro grandes industrias de relevancia nacional: dos cementeras, una de agua mineral y una cervecera. En un radio a $30 \mathrm{~km}$ de la ciudad hay una decena de sitios turísticos de un gran valor ambiental. Desde 2010 "Destino Minas" incrementó en más de $350 \%$ la visita de turistas.

Ingresando al tema que nos ocupa, desde 2004 rige en Lavalleja y su capital Minas, la Ordenanza de Desarrollo y Ordenamiento Territorial del Departamento de Lavalleja. La normativa nacional en el tema es reciente y ha sido delegada en sus 19 Departamentos. Desde 2008 rige la ley 18308 de Ordenamiento Territorial y Desarrollo Sustentable a cargo de la DINOT Dirección Nacional de Ordenamiento Territorial, dependiente del Ministerio de Vivienda, Ordenamiento Territorial y Medio Ambiente. Como primer paso de aplicación de la ley 18308 la Intendencia de Lavalleja y la DINOT elaborarondo las Directrices Departamentales de Ordenamiento Territorial y Desarrollo Sostenible, las cuales se encuentran en etapa de aprobación previa; así como las Directrices Regionales de Ordenamiento Territorial y Desarrollo Sostenible, las cuales se encuentran aprobadas. La fase actual -2013-2014- corresponde a la formulación y puesta en marcha del Plan Local de Minas, que incluye las Zonas Urbana, Sub-urbana y el Área Potencialmente Transformable propuestas en las Directrices Departamentales. (IDL, 2014:5-6)

Entre las nutrientes del Plan Local de Minas cabe mencionar las siguientes: 1) Ordenanza de Desarrollo y Ordenamiento Territorial vigente desde 2004; 2) Plan de Ordenamiento Territorial de la Ciudad de Minas, Tomo II (1999); 3) Plan 
Estratégico de la Microrregión de Minas (2001); 4) Censo Nacional de Población y Vivienda, Instituto Nacional de Estadística; 5) Documento Integración Regional Este, Programa de Cohesión Social; 6) Serie de Informes Departamentales de Lavalleja referentes al mercado de trabajo de diversas instituciones; 7) Directrices Departamentales de Ordenamiento Territorial (2012); 8) Investigación de campo, relevamiento y diagnósticos (comisiones barriales, mesas de seguridad, mesa inter-institucional, consejo social, reuniones con instituciones, etc); y 9) Método Stlocus en Minas y alrededores: Resultados y aplicaciones. Se ha comenzado a aplicar Territorii durante el año 2014.

\section{III.3.b. Stlocus, lugares y zonas de la norma: Aportes directos al Plan Local}

Durante el año 2013, en el marco de la "Formación Inteligencia Territorial Uruguay 2012-2015", el Observatorio OIDTe Lavalleja de Inteligencia y Desarrollo Territorial, junto al Laboratorio TAG IdIHCS UNLP-CONICET de Argentina, en el marco del Convenio entre la IDL y la INTI Network, aplicaron el método científico Stlocus para describir y explicar lugares en la micro-escala para la Ciudad de Minas y sus alrededores: como resultado del trabajo se definieron 39 diferentes lugares, 22 de ellos urbanos y 17 periurbanos, estos últimos coincidentes con los espacios suburbanos de la ley 18308 citada. En la definición de las zonas propuestas para el Plan Local los resultados de esta investigación -los 39 lugares y sus características- fueron de gran utilidad. En definitiva se produjo un diálogo entre, por un lado, las siete fases, los siete criterios y los tres resultados del método Stlocus, con - por otro lado- el trabajo de la Dirección de Arquitectura y Ordenamiento Territorial-con participación de la DINOT- referido a los criterios y variables urbanísticas y constructivas definidas para el objeto propio del Plan Local; otros límites de importancia considerados fueron los referidos a los barrios de la Ciudad de Minas.

Stlocus se aplicó respetando siete momentos, disponibles en www.lavalleja.gub.uy clic en "Formación IT Uruguay". Luego de conformado el grupo, delimitado el territorio de trabajo y conociendo los contenidos del método, sus conceptos, sus variables y el cómo encarar y hacer la tarea (primer momento), se trabajó con el grupo de Lavalleja en el acuerdo de los criterios y su viabilidad para confeccionar el diseño del método (segundo momento). Los criterios acordados fueron siete: 1) Considerar, acordar y definir usos reales del suelo que fueran representativos de la realidad territorial de Minas y alrededores, así como del resto del territorio de Lavalleja, y a la vez manifestación de los principales sistemas de objetos y sistemas de acciones (SANTOS, 2000:53-74) y de las formas de ocupación y apropiación territorial coherentes con aquellos sistemas 
(Bozzano y Resa, 2009:5) Recordemos que el lugar es entendido como la unión entre objetos y acciones, fijos y flujos, ocupación y apropiación, materialidades y prácticas; 2) Considerar y respetar los límites de los barrios, por ende la identidad barrial, procurando obtener el mapa posible representativo posible de los barrios de la ciudad, dado que generalmente nunca existe un solo mapa de barrios en cada ciudad. Con posterioridad, en un taller abierto a la ciudadanía se obtuvieron valiosos aportes sobre los límites de algunos barrios; 3) Considerar íconos, hitos y símbolos urbanos, periurbanos y rurales, tales como parques plazas, escuelas, hospitales, sitios turísticos, clubes, industrias, establecimientos productivos, almacenes, esquinas, boliches. Se trata de lugares representativos para los habitantes que proporcionan información muy útil para reconocer espacialidades relacionales; 4) Considerar los canales por donde circula la gente (accesibilidad) en territorialidades urbanas, periurbanas y rurales, a pie, bicicleta, en ómnibus y/o en vehículo particular. Se trata de un mapa que proporciona información muy útil para reconocer grados de accesibilidad y de conectividad, entendidas éstas respectivamente como acceso de la gente y conexión física por calidad de vías; 5) Considerar la densidad de población por unidad territorial de menor tamaño. Se trata de un mapa que proporciona información útil para reconocer grados de densidad de población residencial variados en los lugares residenciales urbanos y periurbanos; 6) Considerar el mapa con la provisión de servicios públicos urbanos: 1, energía eléctrica, 2 agua corriente, 3 pavimento, 4 desagües cloacales, 5 alumbrado público (luminarias), 6 desagües pluviales y 7 recolección de residuos. Se trata de un mapa que proporciona información útil para reconocer los efectos útiles de aglomeración urbana; y 7) Considerar las formas de relieve, la hidrografía, así como los lugares inundables y con otras formas de fragilidad ambiental: el tipo de vivienda, la contaminación aérea de las grandes fábricas de cemento y otros aspectos. Se trata de un mapa que proporciona información útil para reconocer diferentes tipos de vulnerabilidad y/o riesgo.

El acuerdo en los criterios consignados permitió definir la realización o la búsqueda y obtención de los siguientes mapas temáticos ( tercer momento ): 1) Usos del suelo reales; 2) Barrios y sus límites; 3) Iconos urbanos y periurbanos; 4) Canales de circulación de las personas; 5) Densidad de población (censo 2011); 6) Cobertura de servicios públicos (colección de cartas temáticas analíticas); y 7) Relieve, hidrografia, lugares inundables y con otras fuentes de fragilidad. Una vez obtenidos los mapas temáticos, entonces en el cuarto momento se procedió a trabajar en la articulación entre los conceptos del método -presentes en un Glosario de Términos para quienes desconocían el método- y el ánalisis y la interpretación de dichos mapas, en un proceso de reconocimiento en el mapa de los lugares de manera preliminar -los denominados 'Pre-lugares'- para finalmente definir los lugares. Los últimos tres momentos refirieron a la obtención de 
resultados. la "Realización de Mapas Temáticos con los Límites de los Lugares" (quinto momento), la "Elaboración de Correlaciones entre Lugares y Variables" (sexto momento) y la "Elaboración de Fichas de Lugares" (séptimo momento)

Quinto momento: En resumen los resultados para la Ciudad de Minas y sus alrededores fueron los siguientes. Lugares Urbanos: 1- Microcentro; 2- Centro; 3- Centro Plaza Rivera; 4- Casco Urbano Mixto; 5- Corredor; 6- Centro barrial en desarrollo; 7- Centro barrial germinal; 8- Casco urbano consolidado; 9Residencial con densidad media-alta; 10- Residencial en complejo habitacional densidad alta; 10- Residencial en complejo habitacional densidad baja; 12- Residencial de la Diagonal del Barrio Olímpico; 13- Residencial-jardín abierto en medio urbano; 14- Residencial-jardín cerrado en medio urbano; 15- Residencial con densidad media-baja; 16- Residencial con vulnerabilidad social (viviendas precarias); 17- Residencial con vulnerabilidad ambiental (inundable, ruidos, polvillos); 18- Espacio público recreativo; 19- Grandes equipamientos urbanos; 20Industrial, logístico y afines; 21- Interstícios urbanos aptos; y 22- Interstícios urbanos inundables. Lugares Periurbanos (coincidentes con zonas suburbanas de la Ley 18308/08): 23- Periurbano residencial de baja densidad; 24- Periurbano residencial de baja densidad con vulnerabilidad ambiental; 25 - Residencial-jardín en grandes predios; 26- Residencial-jardín en predios menores; 27- Residencial con fines turísticos; 28- Equipamiento recreativo y/o religioso público; 29- Otros equipamientos en medios periurbanos; 30- Producciones periurbanas intensivas (Huertas, Invernáculos y Viveros); 31- Periurbano con forestación inducida; 32Grandes Industrias Cementeras; 33- Pequeñas y Medianas Industrias y Grandes depósitos en medio periurbano; 34- Vertedero; 35- Periurbano con usos mixtos; 36- Periurbano en valorización en borde urbano; 37- Periurbano vulnerable en borde urbano; 38- Periurbano en valorización por vía de comunicación; y 39- Periurbano débil (límite con lugares rurales)

Sexto momento: La denominada "Matriz-Síntesis" resume las valoraciones que surgen del cruce o correlación entre cada uno de los 39 lugares y las variables urbanas y periurbanas (suburbanas de la ley 18308) presentes en Minas y alrededores. La lectura, el análisis y la interpretación de la matriz contribuye a identificar lugares con características determinadas más o menos comunes, así como también el grado de significación de cada variable. Esto quiere decir que las lecturas pueden comenzarse en el sentido de las filas y pasar a las columnas; o bien hacerlo en el sentido de las columnas y luego pasar a las filas. (FIGURA 2)

Séptimo momento: La elaboración de las "Fichas de Lugares" fue la tarea más compleja: incluyen imágenes, características, problemas y soluciones. En www.lavalleja.gub.uy clic en "Formacion IT Uruguay" puede consultarse el 
cómo se trabajó en los criterios de tomas de fotos e imágenes, el cómo se trabajó en la elaboración y redacción de las características de cada lugar, y el cómo se trabajó en la elaboración y redacción de los problemas y de las posibles soluciones. Se pueden consultar los tres resultados de la investigación en http://territoriosposibles.fahce.unlp.edu.ar clic en Método Stlocus

III.3.c. Stlocus, fundamento teórico del modelo territorial y los escenarios propuestos

El fundamento teórico que orientó la formulación de este trabajo refiere al reconocimiento de lógicas de producción del espacio en Minas y sus alrededores -centralidades, residenciales, industriales, espacios públicos y otras- las cuales fueron claves para explicar tanto el modelo territorial minuano, como para definir tanto los escenarios tendenciales como los escenarios deseables. Asimismo las Zonas y Subzonas del Plan Local son la interpretación y aplicación en la práctica del modelo y los escenarios mencionados. De manera preliminar, las lógicas de producción de espacio son formas para entender cómo se genera, produce o construye cada espacio tanto en ciudades, como en periferias urbanas y en espacios rurales. Se trabaja reconociendo micro-procesos dentro de procesos más amplios: de metropolización, de urbanización, de periurbanización o de organización territorial de espacios rurales, los cuales permiten entender cómo se van produciendo, construyendo y deconstruyendo pedazos, recortes o partes de una ciudad, una periferia urbana o un territorio rural: sus fijos, sus flujos, sus relaciones de poder, sus actividades económicas, sociales y culturales, sus íconos y símbolos, sus conflictos, sus solidaridades, etc. El sentido de la palabra lógica refiere a que cada una de estas formas de producción, generación o construcción de espacio guarda una cierta lógica u orden, diferente de las demás. En el caso del Método Stlocus aplicado a Minas y alrededores en el año 2013, y al resto del territorio del departamento de Lavalleja en el 2014, se trata de conceptos intermediarios entre aquellos más teóricos, como territorio y lugar, y los más operativos de dicho método, a saber: territorialidades, vocaciones, racionalidades, procesos, tendencias, actores y espacialidades.

En América Latina y Europa hemos reconocido al momento que estas lógicas a su vez están respondiendo a cinco lógicas más amplias o abarcativas. Nos referimos a las lógicas de producción de espacio urbanas, periurbanas, rurales y aquellas donde el grado de antropización en los territorios es tan bajo o nulo que las denominamos territorialidades naturales. En el caso de América Latina hemos reconocido 25 al momento. En buena medida estas lógicas son articuladoras de territorialidades, vocaciones, racionalidades y tendencias, en apretado resumen son las siguientes: Urbanas: 1-central, 2-residencial, 3-industrial y logística, 
4-equipamientos, 5-grandes espacios públicos, 6-turísticas y 7-intersticios urbanos. Periurbanas: 8-producciones primario-intensivas, 9-industrial y logística, 10-barrios de sectores de ingresos bajos y medio-bajos, 11-barrios de sectores de ingresos altos y medio-altos, 12-equipamientos, 13-turísticas, 14-conflictos ambientales y 15-periurbano subutilizado en valorización. Rurales: 16-agropecuaria, 17-forestal, 18-minera, 19-turística, 20-parques naturales, 21 -equipamiento, 22-industrial, 23-conflicto ambiental. Naturales: 24-en alto riesgo por mal manejo del territorio, y 25-con menor riesgo.

Las nutrientes teóricas para definir los criterios que contribuyeron a precisar estas 25 lógicas refieren, en el caso de lugares urbanos y periurbanos preferentemente a la sociología urbana de base marxista, en particular autores como Ch.Topalov (1979), J.LoJKine (1977) y J.LiPIETZ (1977), y la interpretación y aplicación de conceptos tales como efectos de aglomeración urbana, efectos útiles de aglomeración, valor de uso complejo, valor de uso simple y valor de cambio simple. Los efectos útiles de aglomeración urbana no son generados por la sumatoria de los valores de uso simple ni por la sumatoria de los valores de cambio simple de cada lote urbano individual en cualquier localidad o ciudad, sino por los valores de uso complejo, vale decir aquellos en los cuales el estado en su rol de creador de espacio urbano mediante obras públicas tales como vialidades y servicios urbanos, y/u obras públicas concesionadas a terceros; de esa manera se contribuye a producir valorización de espacios urbanos. Para diferenciar las territorialidades urbanas de las territorialidades periurbanas tomamos como criterio algunas variantes en los efectos útiles de aglomeración urbana. Ahora bien, cual es el límite entre la aglomeración urbana y el espacio que siendo urbano o directamente influido por el proceso de urbanización no es estrictamente aglomerado? Como se denomina ese espacio? En ocasiones suburbano, en otras periurbano, en otras rururbano y en otras sub-rural, dependiendo de autores, teorías y normas. En nuestro caso lo denominamos periurbano en la medida que constituye el territorio que es peri-urbano o periférico o adyacente a lo urbano aglomerado. El criterio no es meramente espacial dado que la proximidad a la ciudad genera procesos y tendencias de valorización económica (valor de cambio simple, valor del suelo, rentas diferenciales), valorización social (valor de uso simple, relaciones funcionales de los habitantes del periurbano con la ciudad) y valorización pública (valor de uso complejo, espacios destinados al ocio, el esparcimiento y a otras actividades por parte de los habitantes urbanos).

Asimismo estas 25 lógicas de producción de espacio están respondiendo a procesos de organización territorial en el contexto de las condiciones generales de producción y reproducción que impone el sistema capitalista, en este caso para América Latina. Nos referimos a dos procesos: 1) urbanización-incluidos 
procesos, tanto de metropolización, como de periurbanización- ; y 2) procesos de organización territorial de espacios rurales en el marco dominante del sistema capitalista, incorporando tanto procesos hegemónicos en WiLLIAMs (1980) -agricultura, ganadería, minería y forestación, todas ellas netamente capitalistas, a cargo dominantemente de grandes empresas- como procesos hegemónicos alternativos en Williams (1980), entre ellos representados por pequeños productores, sistemas cooperativos de producción, producciones ecológicas y otras respetuosas y amigables con el medio ambiente. En el caso de la actividad turística también es posible reconocer aquellas más asociadas a procesos hegemónicos y al denominado "turismo-marketing", de aquellas más respetuosas del ambiente y las culturas locales, tanto en lugares urbanos como en periurbanos y rurales. Para diferenciar territorialidades urbanas o periurbanas de rurales o naturales empleamos criterios de uso del suelo y de los circuitos económicos a ellos asociados. En el caso de las territorialidades naturales, con frecuencia tienen lugar procesos en apariencia irrelevantes cuyos escenarios de fragilidad, riesgo y vulnerabilidad muy importantes tienden a producir conflictos sociales y ambientales del mayor calibre: es el caso de buena parte de miles de lugares de la Diagonal Árida Sudamericana entre el Sur de Ecuador y el Norte de la Patagonia, a lo largo de cinco grandes países: Ecuador, Perú, Bolivia, Chile y Argentina. En definitiva, cuando se piensa la producción de espacio en términos de alguna de estas lógicas, comienzan a emerger sus vocaciones y usos reales del suelo generalmente en primer lugar, pero también un gran número de aspectos presentes tanto en los mapas temáticos que realizamos, como en las interpretaciones de otros conceptos operacionales y variables. Las realciones entre lógicas de producción de espacio y los lugares reconocidos en Minas y alrededores, pueden consulatrse en los dos enalces de internet citados.

\section{III.3.d. Stlocus, modelo territorial y escenarios: Aportes indirectos al Plan Local}

El modelo territorial de Minas y sus alrededores es una síntesis que se construye integrando el diagnóstico y la evaluación sectorial -social, cultural, económica, institucional, etc- y los resultados del Método Stlocus vale decir el diagnóstico y la explicación más integral en la micro-escala espacial. Así, el modelo territorial de Minas y sus alrededores contribuye a formular los escenarios tendenciales y los escenarios deseados para las próximas tres o cuatro décadas. Este sendero de diagnósticos, evaluaciones, explicaciones y escenarios es la base para formular la Propuesta del Plan Local de Minas y alrededores. 
Modelo Territorial. La ciudad de Minas, capital del departamento de Lavalleja cuenta con un centro comercial, administrativo, turístico y de servicios, trece pequeños subcentros barriales y más de treinta barrios distribuidos -desde su casco fundacional en damero- preferentemente en torno a tres ejes de crecimiento y expansión urbana que se han ido consolidando en las seis últimas décadas: la Ruta 8 hacia Montevideo, la antigua estación ferroviaria y la Ruta 8 hacia Treinta y Tres. Asimismo, en la última década se insinúa un cuarto eje de crecimiento y expansión sobre la Ruta 12 en dirección a Punta del Este y Piriápolis relacionado con barrios-jardín, residencias con fines turísticos y otras actividades asociadas. Hay un quinto eje de crecimiento, incipiente, en dirección a Florida por la Ruta 12. Dentro del modelo territorial minuano, el espacio suburbano (de acuerdo a la Ley 18308/08) rodea y triplica en superficie al espacio urbano y es dominado por un relieve ondulado, con algunos cerros y cursos de agua, con actividad agropecuaria predominante en un 75 a $80 \%$ que alterna con otras lógicas de producción de espacio: barrios, industrias, equipamientos, espacios recreativos y turísticos, forestación inducida, el vertedero y algunas producciones intensivas. En el modelo territorial urbano, el relieve y la hidrografia, juegan un rol fundamental: una serie de cerros -Artigas, Las Pitas, Partido, Pelado, de la Guardia- en la mitad norte de la ciudad, y de cursos de agua -Arroyo San Francisco y La Plata, Cañadas Zamora, del Coto y otras menores- drenando hacia la mitad meridional de la ciudad organizan ambientalmente un espacio urbano que ha respetado históricamente en general estas condiciones naturales y que es necesario considerar tanto en los escenarios deseables como en las normas y sus indicadores que regirán en las Zonas del Plan Local. Minas tiene alturas que oscilan entre 105 y 225 metros sobre el nivel del mar. Ocho vías contribuyen a organizar y estructurar el territorio urbano y su periferia, acordes ellas a los ejes de crecimiento mencionados.

El modelo territorial del periurbano minuano -suburbano de la ley 18308no registra un grado de organización territorial del calibre del modelo urbano propiamente dicho. Su rasgo dominante es tanto el respeto como el aprovechamiento dado por las condiciones del relieve, la hidrografia superficial y subterránea, así como de sus recursos económicos y paisajísticos de la bien llamada "Capital de las Sierras". Sobresalen dos grandes industrias cementeras, una pública (Ancap) y otra privada (Artigas), dos grandes industrias relacionadas con las fuentes de agua: Salus y FNC Fábrica Nacional de Cervezas, y tres espacios recreativos de significación nacional: el Parque UTE. El Cerro y la Virgen del Verdún y el Parque Salus. En el resto de la periferia minuana predominan predios de uso ganadero, y en menor medida agrícola, forestal y de vivero. Algunos equipamientos, cuatro barrios periféricos, una fábrica mediana y el vertedero completan el modelo territorial. 
Escenarios Tendenciales. En el proceso de organización territorial de Minas y sus alrededores han intervenido principalmente 21 acontecimientos en tiempo-espacio representativos éstos de tanto de su desarrollo urbano y social como de su desarrollo económico. Estos acontecimientos o hitos jalonan unos escenarios tendenciales de todo el territorio minuano y su actual periferia. Un somero análisis de estos hitos permite reconocer que cinco de ellos se relacionan con la propia expansión residencial urbana: el casco histórico de la ciudad y los barrios Estación y Las Delicias, otros tres se relacionan con la accesibilidad y conectividad regional: las Rutas 8 y 12 y el tren, seis hitos se relacionan con el desarrollo económico de Minas: las dos cementeras, Salus, la cervecera, la metalúrgica y el Molino Ugarte, cinco hitos están relacionados con el esparcimiento público, semipúblico o privado: los Cerros Verdún y Artigas, y los Parques Rodó, UTE y OSE, mientras que dos hitos se relacionan con la función militar de la ciudad: los Batallones números 4 y 11. A esta matriz tendencial se agregaron valles $\mathrm{y}$ áreas vulnerables, principalmente por sus condiciones de inundabilidad. También es oportuno considerar otros hitos en la historia social, cultural, institucional y económica de Minas que si bien no tuvieron el impacto de los consignados precedentemente, en su conjunto contribuyeron a definir las tendencias y los escenarios tendenciales más significativos. De esta manera los escenarios tendenciales de Minas y alrededores pueden resumirse de la siguiente manera: 1) Expansión y consolidación urbana central, 2) Expansión y consolidación urbana residencial, 3) Expansión y consolidación industrial, 4) Desarrollo y consolidación de espacios verdes y de esparcimiento, 5) Desarrollo incipiente de espacios turísticos y recreativos, y 6) Fortalecimiento de los estructuradores viales.

Escenarios Deseables. La combinación entre las tendencias más salientes del proceso de organización territorial y los lineamientos de ordenamiento territorial planteados para la ciudad de Minas y sus alrededores, éstos como parte integrante, de las Estrategias Regionales de Ordenamiento Territorial y Desarrollo Sostenible para la región Este, las Directrices Departamentales de Ordenamiento Territorial y Desarrollo Sostenible para Lavalleja, contribuyeron a formular los escenarios deseables. Estos pueden resumirse de la siguiente manera: 1) Desarrollo y consolidación del centro, 2) Consolidación urbana residencial en barrios existentes, 3) Industrias existentes compatibles con sus entornos, 4) Desarrollo y fortalecimiento del Parque Rodó como espacio recreativo y turístico, 5) Desarrollo y fortalecimiento del Cerro Artigas como espacio recreativo y turístico, 6) Asignación de usos compatibles en los ocho intersticios urbanos, 7) Espacio de promoción turística, esparcimiento y segunda-residencia, 8) Promoción de la zona industrial de Paso de las Tropas, 8) Promoción de una nueva terminal de 
ómnibus, 9) Promoción de un espacio con fines universitarios, 10) Promoción de un hotel 4 o 5 estrellas y de circuitos de "bed\&breakfast", 11) Promoción de un plan de arbolado urbano acorde a las aceras, 12) Ordenamiento vial en Rutas 8 y 12,13) Ordenamiento vial de la ciudad, 14) Restricciones constructivas en lugares vulnerables, 15) Restricciones a loteos residenciales tradicionales en las zonas suburbanas, 16) Consolidación de la trama urbana existente y control de la expansión de los límites urbanos, 17) Programa de solución integral nacionaldepartamental al vertedero, y 18) Promoción de un "by-pass" para la ciudad solo para transporte de carga pesada.

\section{CONCLUSIONES}

\section{IV.1 Ordenamiento del Territorio con Inteligencia Territorial}

Considerando trayectorias político-institucionales e historias sociales, económicas y ambientales en América Latina, si el Ordenamiento del Territorio incorpora el compromiso no sólo desde la política, sino desde las otras "patas de la mesa" -comunitaria, económica y científica- tendrá mayores posibilidades de hacerse con Inteligencia Territorial. La insuficiente predisposición a la coconstrucción de proyectos en conjunto en nuestras sociedades está demostrando que el riesgo de continuar con un Ordenamiento Territorial discursivo y alejado de nuestras realidades es mucho mas elevado, que la posibilidad cierta de ejecutar un OT con IT, sentido y co-construido por la gente, que haga mas creibles a los politicos y que la gente lo considere útil. Para hacer un OT con IT es necesario que cada uno, siendo consciente de su posición, aporte y no imponga desde su saber y conocer -político, científico, comunitario o empresario- en lugar de criticar al político porque no hace, al científico porque está en una "burbuja", o así a cada uno de los demás. En este OT, la comprehensión y articulación entre las escalas de trabajo micro, meso y macro juegan un rol fundamental; particularmente en teóricos que no logran descender a la realidad, en ciudadanos que no conocen que un pequeña acción u omisión trasciende la escala de su cuadra o su barrio, en políticos que con su día a día no suelen sentarse unas horas por semana a frenar su parafernalia en la gestión cotidiana, o de empresarios que no piensan que si gana la gente y el territorio, su empresa también ganará. Por ello afirmamos que política, ciencia, técnica, escalas de trabajo y compromiso no solo deben estar presentes, sino generar un espacio-tiempo donde los vectores de decisión sean fruto de miles de pequeñas co-construcciones con las "cuatro patas de la mesa". Es más trabajoso, pero nos dará más satisfacciones. El COUT en La Plata fue prueba de ello. 


\section{IV.2 El proyecto y las herramientas}

En ocasiones el proyecto - entendido como objeto de estudio, intervención y no siempre de transformación- viene definido desde una institución u organización, en otras puede co-construirse entre dos, tres o cuatro "patas de la mesa", mientras que en muchas otras ocasiones tienen lugar situaciones intermedias. En los casos del OT en La Plata y Minas, es lógico que hubo un respeto por las normas y un trabajo acorde a ellas: los territorios legales de Territorii, tanto la norma vigente como la norma a construir. La circunstancia de trabajar con las "cuatro patas" en territorios reales, vividos, pasados, pensados, posibles, concertados e inteligentes ofreció la posibilidad de no supeditar muchos procesos-sociales, institucionales, ambientales, económicos, etc- a una norma; de otra forma hubiera significado minimizar la definición y ejecución de un proyecto más cerca de la gente. En el caso de Stlocus, la circunstancia de investigar sobre lógicas de producción de espacio, territorialidades, vocaciones, racionalidades, procesos, tendencias, actores y espacialidades, asi como en un gran número de variables a ellos asociadas y con un elevado nivel de detalle espacial, contribuyó a dar mayor certidumbre a los acuerdos a los que se quería llegar en materia de Ordenamiento del Territorio. Sin embargo, ni Territorii ni Stlocus son la Biblia ni mucho menos, de allí la importancia de ser conscientes del notable valor de la caja de herramientas: en La Plata y en Minas, por ejemplo, se investigó con muchas otras técnicas. Coincidimos con la conocida afirmación de Pierre Bourdieu, en su obra El Oficio del Sociólogo que "Toda técnica es teoría en acto". Sin embargo, ¿cuánto sabemos acerca de poner en acto las teorías que pretendemos aplicar con qué herramientas? ¿Cuánto conocimiento tenemos acerca de cuáles son los métodos y técnicas que en cada proyecto, siempre único e irrepetible, serán los más oportunos y pertinentes? Entendemos por caja de herramientas a un conjunto de métodos y técnicas de los cuales poder disponer para conocer cuáles y en qué momentos del proceso de investigación son o pueden ser útiles y pertinentes para el objeto, los objetivos y las hipótesis que nos hemos trazado.

\section{IV.3 Con nuevos vectores de decisión: otro poder}

El poder social y el poder del conocimiento no sólo pueden, sino que deben sentarse a la mesa en las mismas sillas, a la par, con los poderes políticos, económicos y de los mass media en cada proyecto: es necesario tomar la decisión de co-construir nuevos vectores de decisión (Bozzano, 2009:190-193) porque así la Humanidad y nuestro Planeta van por mal camino. Es necesario co-construir otro poder. No sólo los Proyectos de OT, sino todos los Procesos de Intervención y Transformación con IT están teñidos por particulares vectores de decisión 
y relaciones de poder, sobre los cuales es necesario indagar desde el comienzo mismo de cada objeto de estudio. Esperamos estar asistiendo a un tiempo de la Historia donde un conjunto de nuevas coaliciones, más abiertas y sustentables, dispuestas a convivir de veras con otras, estén generando mayor certidumbre de estar co-construyendo sin saberlo una inteligencia colectiva-¿imacro-coalición? ¿inteligencia territorial colectiva?- donde los numerosísimos movimientos alternativos al mundo hegemónico se conozcan, respeten y consideren como pares en pos de la construcción de una corriente alternativa más poderosa que la vigente. Utopía, sueño o decisión? La justicia cognitiva global (DE SousA, op.cit) es nuestro desafío y nuestra esperanza para tomar la decisión de cumplir nuestros sueños y estar más próximos a una utopía.

Es evidente que un proyecto donde se busca congeniar entre una mega-minera - $\mathrm{u}$ otra empresa global de agro-químicos, armamentos, etc.- con las comunidades locales afectadas y los ambientes puestos en jaque, están involucrando vectores de decisión muchísimo más complejos que aquellos presentes en proyectos de inclusión social en barrios vulnerables, de desarrollo rural, turismo o jóvenes. Seguramente un proyecto de OT se encuentra a mitad de camino entre ambos. Ahora bien, en cada proyecto, el reconocimiento de los actores de las "cuatro patas de la mesa" de la IT, cada uno con sus astillas más próximas a procesos hegemónicos, contra-hegemónicos y hegemónicos alternativos en WILLIAMs (1980) casi siempre presentes al interior de cada oficina, empresa, organización, comunidad, universidad o lo que sea, nos están planteando un trabajo cuidadoso y "de hormigas" para conocer hacia dónde tira cada actor, explícita o implícitamente. Coincidimos con Williams en que una hegemonía dada es siempre un proceso, y excepto desde una perspectiva analítica, no es un sistema o una estructura; se trata de un complejo efectivo de experiencias, relaciones y actividades que tiene límites y presiones específicas y cambiantes. La "hegemonía" es, según las diferentes interpretaciones, un complejo entrelazamiento de fuerzas políticas, sociales y culturales; $y / o$ las fuerzas activas sociales y culturales que constituyen sus elementos necesarios... Puede argumentarse persuasivamente que todas o casi todas las iniciativas y contribuciones, aún cuando asuman configuraciones manifiestamente alternativas o de oposición, en la práctica se hallan vinculadas a lo hegemónico: que la cultura dominante, por así decirlo, produce y limita a la vez sus propias formas de contracultura. (WiLLIAMS; 1980:170-171) En la medida en que esta interpenetración perdura hace décadas en los ejes de las sucesiones y las coexistencias cotidianas (SANTOS; 2000:134), ¿cómo podremos discernir entonces si nuestras prácticas -científicas, sociales, culturales, políticas- están en tal o cuál de las tres posiciones? Hegemónicas, contra-hegemónicas o hegemónicas alternativas. Conociéndonos en acción -haciendo cada proyecto- tendremos la 
oportunidad de discernir, sin caer en un analisticismo sin fin, qué posición ocupa cada actor.

\section{IV.4 Identidades, necesidades y sueños}

Tal vez estemos, sin saberlo, comenzando a co-construir miles de pequeñas y grandes iniciativas portadoras de justicia cognitiva global por una justicia social global (DE SOUSA, op.cit.) y una justicia ambiental global que intensifiquen la voluntad de una transformación virtuosa en el interior de cada individuo, en nuestra relación con los demás, en nuestra conciencia hacia el ambiente y el territorio, y en la incidencia en unas tomas de decisiones más justas y transparentes.

Hace tiempo, Albert Einstein escribía: "La tarea suprema del físico es llegar a unas leyes universales y elementales a partir de las cuales se pueda construir el cosmos por pura deducción. No hay un sistema lógico para llegar a estas leyes; sólo la intuición, basada en una inteligencia comprensiva, nos permite acercarnos a ellas (...) el estado mental que permite a un hombre realizar un trabajo de esta naturaleza es semejante al del creyente o al del amante: el esfuerzo cotidiano no procede de un programa o de una intención deliberada, brota directamente del corazón";8 como bien señalaba Einstein, “...la imaginación es más importante que el conocimiento”. ¿Podemos generar desde la Ciencia condiciones para que identidades y sueños en el marco de multiculturalidades y biodiversidades "broten directamente del corazón" tal como escribía Einstein hace 96 años? ¿Podremos desarrollar la imaginación -aplicándola con conocimiento- para construir juntos en los próximos 96 años otra alternativa y poner freno al atropello que representa la locura global que estamos cometiendo con nuestros pares y con nuestro Planeta? ¿Estaremos en condiciones de contribuir a que en este "caldo de cultivo multicultural y biodiverso de identidades y sueños" los seres humanos podamos poner más coto al desenfreno consumista y empezar a equilibrar un poco la balanza de las necesidades materiales básicas en más de 3 mil de 7 mil millones de seres humanos? ¿Podremos lograr que 1 de cada 10 proyectos de investigación social en el mundo se co-construyan con la gente en el marco del paradigma emergente articulando teorías sociales, territoriales y de la transformación? ¿Estaremos en condiciones de unirnos entre las más de 300 redes científicas y

8 Albert Einstein, 1918, citado por Hoffman, B. (1984) Albert Einstein. Creator and Rebel. London: Viking Press. Traducción española de J. Fernández , Einstein. Barcelona: Salvat Editores, 1984 (pp. 192-193) 
sociales que hacemos cosas bastante semejantes? ¿Cómo podemos hacer que el $10 \%$ de esto sea posible?

En "El fin de las certidumbres", al referirse a lo posible y lo real, Ilya Prigogine plantea que “...lo posible es 'más rico' que lo real. El universo que nos rodea debe ser entendido a partir de lo posible, no a partir de un estado inicial cualquiera del cual pudiera de alguna manera deducirse." (Prigogine;1996:65) El autor cita el planteo que Bergson hace en Le possible et le réel sobre el tiempo, entendiéndolo como "brote efectivo de novedad imprevisible".

La ejecución de los cuatro planos de la transformación -individuales, sociales, ambientales y decisionales- cada día contribuirán de manera más consciente, y también querida, a promover nuestras identidades, a dar respuesta a nuestras necesidades materiales más acuciantes -alimentación, salud, vestimenta, etc- y serán manifestación que estamos cumpliendo algunos de nuestros sueños. Identidades, necesidades y sueños suponen el respeto a la biodiversidad y a la multiculturalidad

Es muy complejo hoy afirmar en qué dosis teóricas y empíricas nació esta triangulación de identidades, necesidades y sueños que aquí se propone. Nació tanto con antecedentes teóricos -procedentes de la Antropología, la Geografía, la Economía, la Psicología y la Sociología, entre otras disciplinascomo también y sobre todo, en 2010 y 2011, en ocasión de la iniciativa de puesta en marcha del Observatorio OIDTe de Inteligencia y Desarrollo Territorial en Lavalleja, Uruguay, pero también en una docena de talleres en varios países de América Latina: de ellos, en Manzanillo del Mar, Caribe colombiano y en Milagro de Dios, Armenia del Quindío, tal vez lo que "brotaba del corazón" era incontenible. En Lavalleja, a la reflexión y al calor de 74 talleres realizados en todas las latitudes del Departamento, en la escucha a muchísimos de los 1200 actores que participaron, resultó que lo posible y lo real, y lo que "brotaba del corazón" de muchos estaba directamente emparentado con sus identidades, sus necesidades y sus sueños, y así fueron surgiendo preguntas sencillas tales como qué soy, qué necesito, qué quiero, que somos, qué necesitamos y qué queremos, y así también se nos ponía la piel de gallina a muchos, y así también decidíamos tomar la decisión que juntos podíamos cambiar nuestro micro-mundo. 


\section{BIBLIOGRAFIA}

Bachelard, G. (1984): La formación del espíritu cientifico. (1 ${ }^{\text {a }}$ Edición en francés: 1938) México, Siglo XXI

Bozzano, H. (1999): Les territoires de la restructuration industrielle dans la Région Méropolitaine de Buenos Aires. Tesis Doctoral en Geografía, Ordenamiento del Territorio y Urbanismo, Paris, Univ.Sorbonne Nouvelle.

Bozzano, H. (2000): Territorios reales, territorios pensados, territorios posibles. Aportes para una Teoría Territorial del Ambiente. Buenos Aires, Espacio. ( $3^{\text {a }}$ edición: 2012)

Bozzano, H. y Resa, S. (2009): «Places: The Stlocus Method. Its usefulness in diverse intervention projects». Ponencia en VII International Conference of Territorial Intelligence, Acta. (Salerno, 4 al 7 de noviembre de 2009), Universitá di Salerno. En línea: http://halshs.archives-ouvertes.fr/halshs-00533350

Bozzano, H. (2009): Territorios posibles. Procesos, lugares y actores. Buenos Aires, Lumiere. ( $2^{\mathrm{a}}$ ed. 2012.)

Bozzano, H. (2009a): «Cartografias: el Método Portulano. Mapas atractivos donde se justifique trabajar con mapas». Ponencia en VII International Conference of Territorial Intelligence, Acta. (Salerno, 4 al 7 de noviembre de 2009), Universitá di Salerno. En línea: http://halshs.archives-ouvertes.fr/halshs-00533331

Bozzano, H., Karol, J. y Cirio, G. (2009): «Perspectiva EIDT en Entendimiento, Inteligencia y Desarrollo Territorial». Ponencia en I SIIT Seminario Internacional de Inteligencia Territorial, Universidad Nacional de La Plata, Actas (La Plata, 14 y 15 de diciembre de 2009)

Bozzano, H. (Dir.); Girardot, J.J.; Cirio, G.; Barrionuevo, C. y Gliemmo, F. (Coord.) (2012): Inteligencia territorial. Teoría, métodos e iniciativas en Europa y América latina. La Plata: Edulp Editorial Universitaria de La Plata

Bozzano, H. (2013a): «Geografía e Inteligencia Territorial. Geo-grafein, Geo-explanans, Geo-transformare» Revista Geográfica Digital, nº 19, UNNE. En línea: http://hum. unne.edu.ar/revistas/geoweb/default.htm

Bozzano, H. (2013b): «Geografia, Útil de Transformação. O método Territorii, o diálogo com a Inteligência Territorial». Revista Campo e Territorio, vol.8 (n¹6). En línea: http://www.seer.ufu.br/index.php/campoterritorio/issue/current

BozzAno, H. (2014): «Procesos de intervención y transformación con inteligencia territorial. Stlocus y Territorii en la caja de herramientas». Revista Arquetipo, $\mathrm{n}^{\circ} 8$ (en prensa) UCP, Pereira, Colombia

DE IPOLA, E. (2004): El eterno retorno: acción y sistema en la teoría social contemporánea. Buenos Aires, Biblos.

DE Sousa SAntos, B. (2009): Una epistemología del sur: la reinvención del conocimiento y la emancipación social. México, Siglo XXI-CLACSO

FALs Borda, O. (1986): «La investigación-acción participativa: Política y epistemología» en La Colombia de hoy (CAMACHO, A., editor) Bogotá: Cerec, 21-38 
Fals Borda, O. (2009): Una sociología sentipensante para América Latina. Antología 1925-2008. (Moncayo, V.M., Compilador). Bogotá, Siglo del Hombre Editores y CLACSO.

Freire, P. (1996): Pedagogia da Autonomia. Río de Janeiro: Paz e Terra.

Girardot, J. J. (2009): «Evolution of the concept of territorial intelligence within the coordination action of the European network of territorial intelligence». RES Ricerca e Sviluppo per le politiche sociali, vol. 1-2, Salerno, Universitá di Salerno, 11-29.

IDL-INTENDENCIA DEPARTAMENTAL DE LAVALLEJA (2014): Plan Local de Ordenamiento Territorial y Desarrollo Sostenible de la Ciudad de Minas. Documento de Avance. Minas, Uruguay

Lefebvre, H. (1995): Lógica formal. Lógica dialética. Rio de Janeiro, Civilização Brasileira. $\left(1^{\mathrm{a}}\right.$ ed. 1969$)$

Lipietz, A. (1977): Le capital et son espace. París, Máspero

LoJkine, J. (1977): Le marxisme, l'Etat et la question urbaine. Paris, PUF (Presses Universitaires de France).

Long, N. (2007): Sociología del Desarrollo: Una perspectiva centrada en el actor. México, Ciesas-El Colegio de San Luis.

Massiris Cabeza, A. (2002): «Ordenación del territorio en América latina». Scripta Nova. Revista Electrónica de Geografía y Ciencias Sociales. Barcelona, Universidad de Barcelona, 1 de octubre de 2002, vol. VI, n 125 . En línea: http://www.ub.edu/geocrit/ $\mathrm{sn} / \mathrm{sn}-125 . \mathrm{htm}$

MEC-IDL-INTI-CLAEH (2014): Sistematización de Actividades Octubre 2012-Noviembre 2013 “Formación Inteligencia Territorial Uruguay 2012-2015”. Ministerio de Educación y Cultura de Uruguay, Intendencia Departamental de Lavalleja, International Network of Territorial Intelligence e Instituto Universitario CLAEH.

MLP-MUNICIPALIDAD DE LA PLATA (2000): Fundamentos para la convalidación provincial de la Ordenanza de Ordenamiento Territorial 9231 y Uso del Suelo para el Partido de La Plata. La Plata, Sec.Gestión Pública, Subsec. Planeamiento y Desarrollo Urbano, Dirección de Planeamiento (Resa, Sergio, director)

Montero, M. (1984): «La psicología comunitaria: orígenes, principios y fundamentos teóricos». Revista Latinoamericana de Psicología, Konrad Lorenz, Colombia, vol. 16 $\left(n^{\circ} 3\right), 387-400$.

Montero, M. (2004): Introducción a la psicología comunitaria. Buenos Aires, Paidós.

Montes LiRA, P. (2001): «El ordenamiento territorial como opción de políticas urbanas y regionales en América Latina y el Caribe». Medio ambiente y desarrollo, ${ }^{\circ} 45$. Santiago de Chile, CEPAL-ECLAC, diciembre de 2001. En línea: http:/www.eclac.org/ publicaciones/xml/8/9698/lcl1647e.pdf

Pichon-Riviere, E. (1975): Del Psicoanálisis a la Psicología Social. Buenos Aires, Amorrortu.

Pichon-Riviere, E. (1985): Teoría del Vínculo. Buenos Aires, Nueva Visión.

Prigogine, I. (1996): El fin de las certidumbres. Santiago de Chile, Andrés Bello.

Santos, M. (2000): La naturaleza del espacio. Técnica y tiempo. Razón y emoción (1 ${ }^{\mathrm{a}}$ edición 1996). Barcelona, Ariel. 
SAQUET, M. (2013a): «El desarrollo en una perspectiva territorial multidimensional». Revista Movimentos Sociais e Dinâmicas Espaciais, Recife, vol.2 (n 1), 111-123.

SAQueT, M. (2013b) «Por uma abordagem territorial: continuando a reflexão» en Estudos territoriais na ciência geográfica. (SAQUET, M., org.). São Paulo: Outras Expressões, 47-74.

Topalov, СH. (1979): La urbanización capitalista. Elementos para su análisis. México, Edicol

Voloschin, C. (2013): Aportes teóricos de Pichon Riviere a las Ciencias Sociales. Tesis Doctoral en Ciencias Sociales. Facultad de Ciencias Sociales, Universidad de Buenos Aires (inédito)

Williams, R. (1980): Marxismo y literatura. Barcelona, Península.

Wright, E.O. (2010): Envisioning Real Utopias. W.W.Norton \& Co, Estados Unidos. 
